\title{
Biotechnology for Enhanced Nutritional Quality in Plants
}

\author{
Ayse Ozgur Uncu, Sami Doganlar, and Anne Frary \\ Izmir Institute of Technology, Department of Molecular Biology \& Genetics, Urla, Izmir, Turkey
}

Table of Contents

I. INTRODUCTION

II. TARGETS FOR IMPROVEMENT

III. PROTEIN MODIFICATION

IV. CARBOHYDRATE ENGINEERING

V. FATTY ACID MODIFICATION

VI. VITAMIN AND ANTIOXIDANT CONTENT ENGINEERING

A. Vitamin A

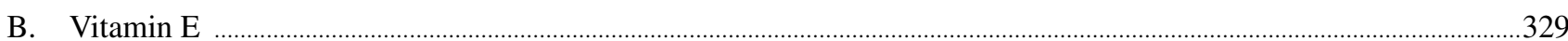

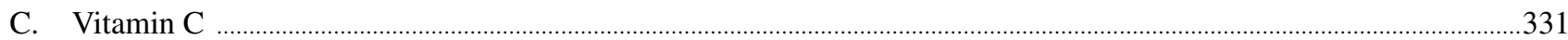

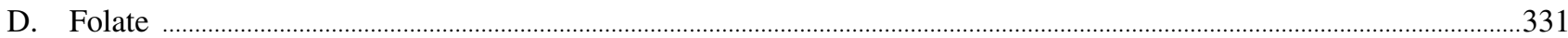

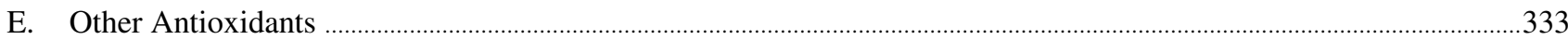

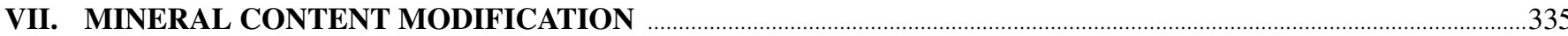

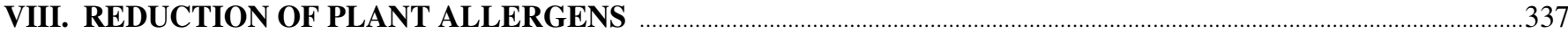

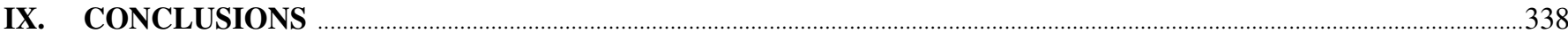

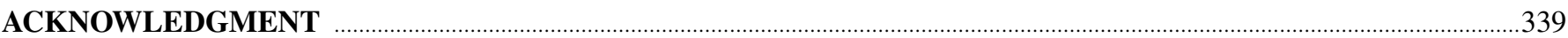

REFERENCES

With almost 870 million people estimated to suffer from chronic hunger worldwide, undernourishment represents a major problem that severely affects people in developing countries. In addition to undernourishment, micronutrient deficiency alone can be a cause of serious illness and death. Large portions of the world population

Address correspondence to Anne Frary, Izmir Institute of Technology, Department of Molecular Biology \& Genetics, Urla, Izmir 35430 Turkey. E-mail: annefrary@iyte.edu.tr rely on a single, starch-rich crop as their primary energy source and these staple crops are generally not rich sources of micronutrients. As a result, physical and mental health problems related to micronutrient deficiencies are estimated to affect around two billion people worldwide. The situation is expected to get worse in parallel with the expanding world population. Improving the nutritional quality of staple crops seems to be an effective and straightforward solution to the problem. Conventional breeding has long been employed for this purpose but success has been limited to the existing diversity in the gene pool. However, biotechnology enables addition or improvement of any nutrient, even those that are 
scarce or totally absent in a crop species. In addition, biotechnology introduces speed to the biofortification process compared to conventional breeding. Genetic engineering was successfully employed to improve a wide variety of nutritional traits over the last decade. In the present review, progress toward engineering various types of major and minor constituents for the improvement of plant nutritional quality is discussed.

Keywords antioxidants, carbohydrates, fatty acids, folate, genetic engineering, minerals, proteins, vitamins

\section{INTRODUCTION}

According to the United Nations Food and Agriculture Organization (FAO), an estimated 868 million people were undernourished in the years from 2010 to 2012 (FAO, WFP and IFAD, 2012). Undernourishment in combination with vitamin and mineral deficiencies is responsible for the deaths of more than 2.5 million children per year (FAO, WFP and IFAD, 2012). Moreover, vitamin and mineral deficiencies alone affect around two billion people worldwide, increasing the risk of death and serious illness, causing cognitive defects in children and reducing productivity in adults (FAO, WFP and IFAD, 2012). With a population that is expected to reach eight billion by 2025 (UN Population Division, 2011), these problems are only expected to get worse. One solution to this problem is to improve the nutritional quality of staple crops. Although they provide most of the calories and protein for people in developing countries, staple crops such as rice, maize, wheat and bean are not nutritionally complete foods (Hirschi, 2009). As a result, the exclusive consumption of such species can result in vitamin and/or mineral deficiency. For example, people with rice-based diets are more likely to suffer from vitamin A and iron deficiency because rice is a poor source of these nutrients (Bhullar and Gruissem, 2013).

Although conventional breeding has addressed these problems in various crops, progress is slow and limited by the genetic diversity available in a given crop's gene pool (Hirschi, 2009). Biotechnology holds promise for more dramatic improvements in plant nutritional quality, as the gene pool for genetic modification is virtually unlimited (Hirschi, 2009). Thus, it is feasible to introduce an entirely new biosynthetic pathway into a plant to achieve the bioaccumulation of a target phytonutrient. However, to determine if a specific goal is met, the correlation between bioaccumulation and bioavailability must be addressed.

\section{TARGETS FOR IMPROVEMENT}

Plants provide a diverse array of chemicals important in the human diet (Hirschi et al., 2009). These phytochemicals can be divided into two groups based on their abundance in the plant (Grusak, 2002a). Major constituents are present in grams (g) per $100 \mathrm{~g}$ of food product and include proteins, carbohydrates and lipids (Grusak, 2002a). Minor components are found in micrograms or milligrams per $100 \mathrm{~g}$ of food and include vitamins, minerals and health-enhancing secondary metabolites such as antioxidants (Grusak, 2002a).

Genetic engineering of both types of constituents is possible; however, it is generally considered that alterations in quantities of major constituents are much more difficult than quantitative changes in minor constituents (Grusak, 2002a). This is because quantitative changes to major components require the diversion of a substantial amount of precursor(s) from other pathways and may present a storage problem. As a result, modification of proteins, carbohydrates and lipids has largely been confined to qualitative changes. For example, the fatty acid synthesis pathway has been engineered to produce a healthier profile of polyunsaturated fatty acids in oil crops (Singh et al., 2005). In addition, much progress has been made in accumulating long chain omega-3 fatty acids in oil-seed crops (Napier and Graham, 2010). Significant alterations in both quantity and quality of minor components are widely reported. In the following sections, progress toward engineering various types of major and minor constituents for the improvement of plant nutritional quality is discussed.

\section{PROTEIN MODIFICATION}

Humans can synthesize only ten of the twenty amino acids (van der Meer et al., 2001). Therefore, the remaining amino acids must be obtained through diet. In the human body, amino acids are used for protein synthesis and are the precursors to other important molecules including neurotransmitters, hormones and pigments (van der Meer et al., 2001). The proteins of most major crop species including many cereals and legumes are nutritionally poor because they contain low levels of essential amino acids, particularly the members of the aspartate family, lysine and methionine (Hirschi, 2009). For example, maize seeds contain four classes of proteins: prolamins (which comprise $60 \%$ of total seed protein), glutelins (34\%), albumins (3\%) and globulins (3\%) (Salamini and Soavc, 1982). Although the other proteins all contain relatively balanced profiles of amino acids, the predominant proteins, prolamins (also called zeins), have almost no lysine and tryptophan (Coleman and Larkins, 1999). As a result, maize seeds contain very little lysine and tryptophan. Over the years, much effort has been devoted to breeding maize lines with improved amino acid content (Scott et al., 2004). For example, zein mutants (opaque-2 and floury-2) were identified that synthesize less zein protein (Christianson et al., 1974). As a result, the relative content of the nutritionallybalanced proteins is increased and the mutants contain higher levels of lysine and tryptophan (Coleman and Larkins, 1999). Unfortunately, the mutants also have softer endosperm, which increases mechanical damage and disease susceptibility and decreases yield. On the other hand, the results of a recent study with maize opaque-2 nearly isogenic lines suggests a genotype dependent role of opaque-2 rather than being an absolute determinant of zein synthesis and kernel lysine content 


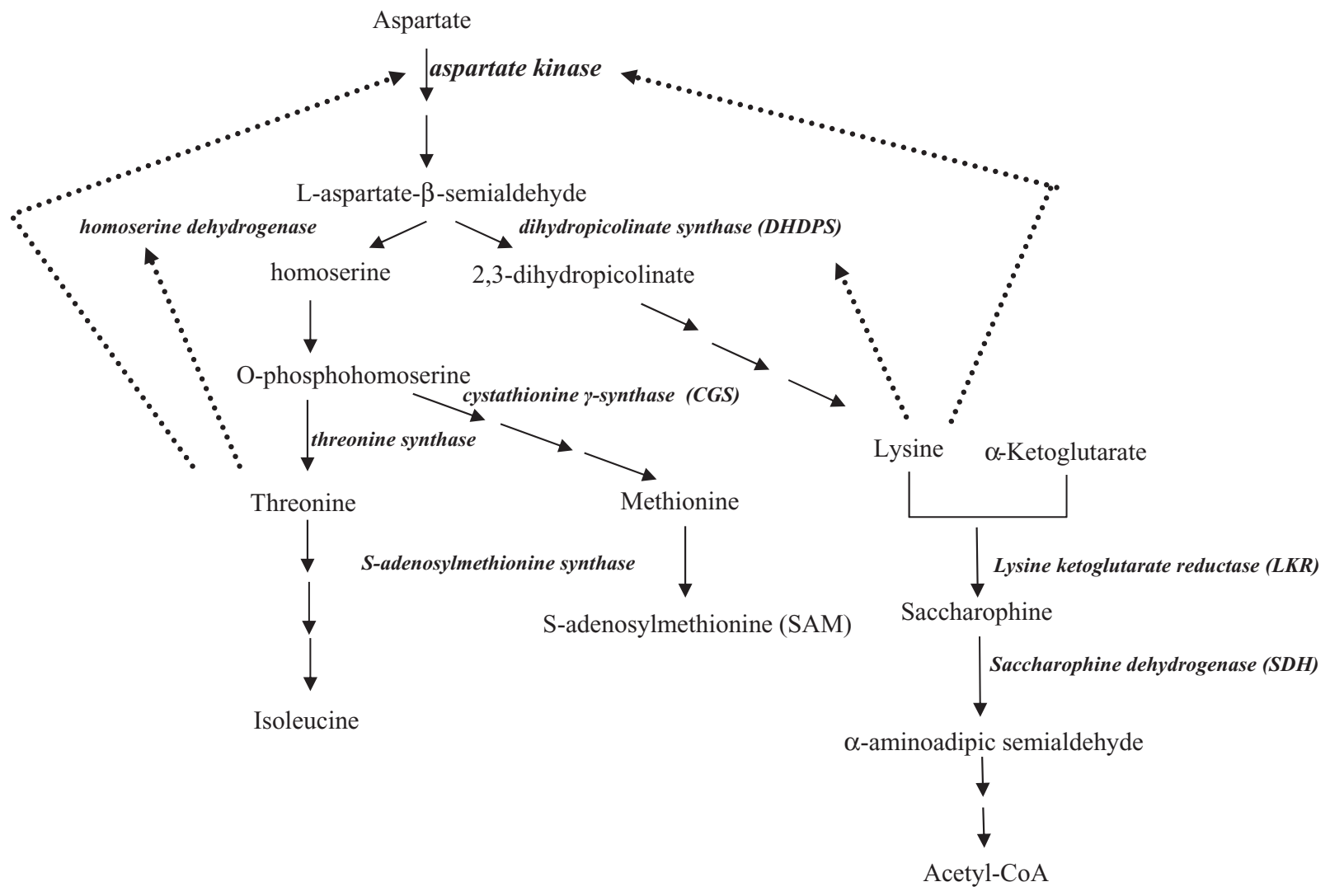

FIG. 1. Schematic biosynthetic pathway for amino acids in the aspartate family and lysine catabolism. Only key enzymes are included (in italics). Feedback inhibition by threonine and lysine is indicated by dotted lines.

(Zhao et al., 2012). Thus, the use of these mutants to breed maize with improved protein content is difficult.

An alternative approach for maize protein modification was described by Huang et al. (2004). In this work, sense and antisense sequences from a $19 \mathrm{KDa} \alpha$-zein gene were introduced into maize to silence endogenous $\alpha$-zein production. The seeds of the resulting transgenic plants had reduced $\alpha$-zein content and altered amino acid profiles. Specifically, lysine, tryptophan, methionine and aspartic acid levels increased while proline and leucine levels decreased. Because the lysine biosynthetic pathway is subject to feedback inhibition by both lysine and threonine (Figure 1), increased lysine production in crop plants has also been achieved by the introduction of feedbackinsensitive biosynthetic enzymes (Mazur et al., 1999). For example, tuber-specific expression of such a dihydrodipicolinate synthase (DHDPS) gene in potato resulted in a six-fold increase in tuber lysine content (Mazur et al., 1999). As can be seen from Figure 1, a feedback insensitive aspartate kinase gene might also be useful for upregulating lysine, methionine and tryptophan production in plants. Another approach to establish high amounts of lysine accumulation in maize endosperm is the seed-specific down regulation of lysine catabolism. Houmard et al. (2007) targeted the bi-functional maize lysine degradation enzyme, lysine-ketoglutarate reductase/saccharopine dehydro- genase (ZLKR/SDH), with the endosperm specific expression of an inverted repeat sequence of the encoding gene. Endosperm specific RNAi silencing of $Z L K R / S D H$ was achieved and resulted in a 20-fold increase in free lysine content of homozygous $\mathrm{F}_{3}$ seeds with respect to non-transformed controls. Frizzi et al. (2008) applied both approaches, endosperm-specific introduction of a feedback insensitive DHDPS and suppression of $L K R / S D H$ expression by transforming maize with a feedback insensitive Corynebacterium glutamicum (CordapA) DHDPS expression cassette having an inverted repeat sequence from maize $L K R / S D H$ inserted in its intron. The combined approach of deregulating lysine synthesis and suppressing its catabolism was successful with as much as 4000 ppm free lysine accumulated in maize seeds. Reyes et al. (2009) combined endospermspecific suppression of maize $L K R / S D H$ with embryo-specific suppression of the gene, which resulted in a synergistic increase in maize seed free lysine content.

While cereals are poor sources of lysine, legumes are particularly poor in the essential amino acid, methionine (Hirschi, 2009). Research on the regulation of methionine biosynthesis promises to be useful for the biofortification of this essential amino acid. Because the methionine and threonine biosynthetic pathways branch from the same precursor, suppressing threonine synthase (TS) leads to increased methionine production 
(Galili and Amir, 2012). However, improvement is at the expense of threonine production, limiting the usefulness of this strategy (Ufaz and Galili, 2008; Galili and Amir, 2012). Cystathionine $\gamma$-synthase (CGS) is the first and key enzyme in methionine biosynthesis (Galili and Amir, 2012). In plants, CGS was shown to have an $\mathrm{N}$-terminal region of approximately 100 amino acids that does not contribute to the catalytic activity of the enzyme (Hacham et al., 2002). The N-terminal region comprises two subdomains that downregulate CGS expression in response to the accumulation of methionine and its metabolite, S-adenosylmethionine (SAM). The first subdomain, methionine over accumulation (MTO1), posttransciptionally regulates the level of $C G S$ mRNA in response to the accumulation of SAM, and is conserved in all plant species. A second methionineresponsive subdomain (30 amino acids) was discovered and characterized in Arabidopsis (Hacham et al., 2006). Interestingly, in addition to the full length form of CGS, Arabidopsis has an additional form of CGS (D-AtCGS) that lacks the 30 amino acid subdomain which presumably ensures that methionine levels are sufficient for the production of metabolites regardless of feedback inhibition (Hacham et al., 2006). However, it is important to note that regulation of methionine biosynthesis may not be conserved in all plant species (Ufaz and Galili, 2008).

Overexpression of the full length CGS and its truncated forms was used in several studies to investigate the regulation of methionine biosynthesis and/or to produce plants with increased levels of methionine (Avraham et al., 2005; Hacham et al., 2008; Dancs et al., 2008). Alfalfa (Medicago sativa L.) is a member of the Fabaceae family that is grown and used worldwide as livestock feed. In order to improve the nutritional quality of this important forage crop, Avraham et al. (2005) produced transgenic alfalfa plants that expressed Arabidopsis CGS (AtCGS). The Arabidopsis Rubisco small subunit promoter was used to direct transgene expression to leaves. Compared to wild type, soluble and water-soluble protein-bound methionine content increased 32-fold and 2.2-fold, respectively, in transgenic plants. Hacham et al. (2008) produced double transgenic plants that co-expressed a feedback insensitive aspartate kinase (bAK) with full length (F-AtCGS), N-terminus deleted (T-AtCGS) and 30 amino acid subdomain deleted (D-AtCGS) forms of the Arabidopsis enzyme. Methionine and threonine biosynthesis pathways branch from the common substrate Ophosphohomoserine (OPH). So, a feedback insensitive aspartate kinase was used to ensure that sufficient levels of the common substrate could accumulate. The double transgenic lines that overexpressed T-AtCGS and D-AtCGS had significantly higher levels of methionine and threonine compared to wild type plants with the latter lines being superior in terms of both improved amino acid accumulation and phenotypic characteristics. While overexpressing T-AtCGS can lead to severe developmental retardation and stunted growth (Hacham et al., 2006), transgenic lines that co-expressed bAK and methionine-feedback insensitive D-AtCGS displayed slight phenotypic abnormalities with 176-fold, 39-fold, and 3.5-fold improved methionine, threonine and lysine contents compared to wild type. Dancs et al. (2008) used the Arabidopsis $D$-AtCGS gene in combination with the methionine rich $15-k D \beta$-zein gene in order to improve methionine content and its incorporation into storage protein in potato tubers. Constitutive expression of the deleted $C G S$ and $15-k D$ $\beta$-zein genes improved free methionine content by only two- to six-fold, with increased methionine content of the zeincontaining protein fraction. In addition to the inadequate improvement of methionine accumulation, transgenic plants had severe phenotypic abnormalities including growth retardation and reduction in tuber yield. Interestingly, transgenic tubers had reduced anthocyanin pigmentation, implying a link between methionine and anthocyanin biosynthesis that requires further investigation. Because legumes are poor sources of methionine, Hanafy et al. (2013), transformed two legume species, soybean (Glycine max) and azuki bean (Vigna angularis) with a mutated form of $A t C G S$ that is insensitive to feedback inhibition by SAM. The mutated gene, AtCGS1 mtol-1, was expressed under the control of a seed-specific glycinin promoter. Although soluble methionine levels increased by two-fold in transgenic seeds of the two species, total methionine content did not increase. In addition, total methionine content of azuki bean seeds significantly decreased compared to wild type, suggesting differential regulation of methionine biosynthesis in the two legume species. Inhibiting methionine catabolism through suppression of the first and main catabolic enzyme, SAM synthase, resulted in dramatic improvements in methionine accumulation. However, severe phenotypic defects accompanied reduced SAM accumulation due to the depletion of several SAM-derived essential plant metabolites (Ufaz and Galili, 2008; Galili and Amir, 2012). Another promising strategy is the expression of natural or synthetic proteins rich in methionine and/or lysine (Galili and Amir, 2012). However, the successful adoption of this strategy depends on several factors such as digestibility, stability, toxicity, allergenicity and effects on seed biology (Ufaz and Galili, 2008; Galili and Amir, 2012).

Cassava (Manihot esculenta) is a starchy root-crop on which more than 250 million Africans rely as their primary energy source and is considered a "food security crop" with its beneficial agronomic properties and high energy production per unit area (Sayre et al., 2011). Having the lowest protein:energy ratio among staple crops, cassava is an attractive target for nutritional quality improvement. One major aim of The BioCassava Plus Program (Sayre et al., 2011) is the accumulation of storage proteins with known amino acid profiles in tuberous roots, thus transforming cassava to a primary calorie source that supplies a nutritionally balanced storage protein. In addition to the complexity of cassava breeding, no significant variability in protein content exists in cassava germplasm (Abhary et al., 2011). Thus, conventional crop improvement methods are not viable for this type of nutritional improvement in cassava (Abhary et al., 2011).

Cassava leaves synthesize linamarin, a toxic cyanogenic glycoside that is transported to roots (Sayre et al., 2011). Cyanide, which is derived from linamarin, is the major source of reduced 


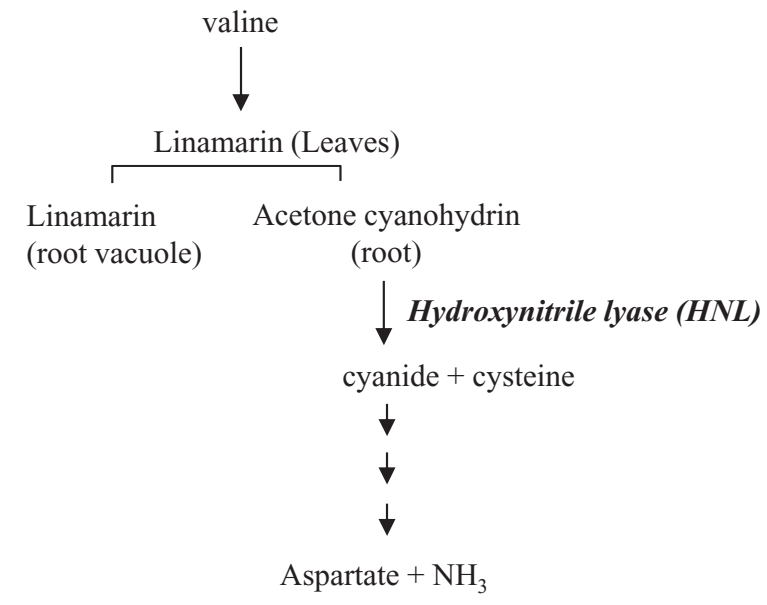

FIG. 2. Schematic representation of linamarin metabolism in cassava.

nitrogen for amino acid synthesis in cassava roots (Siritunga and Sayre, 2004). Linamarin metabolism in cassava is illustrated in Figure 2. Modification of linamarin metabolism towards creating a protein sink in roots would potentially improve total protein content in cassava root (Sayre et al., 2011). Transgenic lines expressing cassava hydroxynitrile lyase $(H N L)$, the enzyme that catalyzes the conversion of acetone cyanohydrin to cyanide, were produced (Siritunga and Sayre, 2004; Sayre et al., 2011). Expression of $H N L$ under the control of the patatin promoter resulted in a three-fold increase in root total protein content. In addition, an $80 \%$ decrease in total root linamarin content was observed, without any reduction in leaf linamarin levels. Sustaining leaf linamarin levels is beneficial for the plant as linamarin provides protection against herbivores. Another advantage introduced by $H N L$ overexpression in cassava roots was the accelerated conversion of acetone cyanohydrin to volatile cyanide, leading to the reduced potential toxicity of cassava foods (Siritunga and Sayre, 2004; Sayre et al., 2011). A second approach towards the same objective was the expression of a chimeric storage protein (zeolin) in cassava roots (Abhary et al., 2011). The chimeric protein combines phaseolin from common bean (Phaseolus vulgaris) and gamma zein from maize (Zea mays) and was shown to make protein bodies in the endoplasmic reticulum. Transgenic plants expressing the chimeric storage protein driven by the patatin promoter displayed an approximately four-fold increase in total protein content $(12.5 \%$ of dry weight) with a 55\% reduction in root linamarin content when compared to wild type plants. Vitamin A content is also a target for improvement in the BioCassava Plus program, and will be described in the relevant section of this review (Sayre et al., 2011).

\section{CARBOHYDRATE ENGINEERING}

Carbohydrates like starch are the most important source of calories in the human diet (Morell and Myers, 2005). Therefore, improvements or alterations in the carbohydrate content of food crops can have dramatic effects on human health and nutrition. One goal is the engineering of resistant starches (Morell and Myers, 2005). Resistant starch is the portion of the starch that passes from the small intestine into the large intestine (Morell and Myers, 2005). In the large intestine, bacterial fermentation of this starch produces short chain fatty acids. These fatty acids are reported to be beneficial for maintaining gut health and preventing colo-rectal cancer (Topping and Clifton, 2001). For example, inulin, a well-studied fructan, is a resistant starch that is fermented in the colon (Sevenier et al., 2002). The consumption of inulin is associated with increases in bifidobacteria, bacteria that are associated with reduced growth of pathogenic bacteria, decreased cholesterol and increased production of vitamin B. Inulin is also reported to improve blood lipid composition and mineral uptake and decrease the incidence of colon cancer. Also of interest are starches that are slowly digested in the small intestine (Morell and Myers, 2005). Such starches provide a steady flow of glucose into the blood and decrease the body's need for insulin. Thus, these starches may be helpful for controlling certain types of diabetes.

Starch biosynthesis is a very complex process with four groups of enzymes required for normal synthesis (Morell and Myers, 2005). Because plants usually have multiple isoforms of each enzyme, starch synthesis requires a minimum of 14 genes including two ADP-glucose pyrophosphorylases, five starch synthases, three starch-branching enzymes and four starchdebranching enzymes (Morell and Myers, 2005). Despite the genetic complexity of starch biosynthesis, there are reports of successful starch modification. In one such study, Sevenier et al. (1998) engineered sugar beet to produce fructan, a polymer of fructose. Sugar beet was selected because it produces large amounts of sucrose, a precursor for fructan production. A gene for fructan synthesis, sucrose:fructosyltransferase, was isolated from Jerusalem artichoke (Helianthus tuberosus) and transferred to sugar beet. Transgenic plants converted $90 \%$ of the sucrose stored in the root to fructans.

Since amylose, the linear, infrequently branched portion of starch, resists digestion, high amylose food products tend to display higher resistant starch content (Regina et al., 2006). The correlation between amylose and resistant starch content provides a strategy for the improvement of starch composition toward a more favorable direction by modifying the amylose/ amylopectin ratio. Down-regulating genes encoding starchbranching enzymes proved successful in increasing the amylose portion of starch in wheat endosperm. Regina et al. (2006) silenced starch-branching enzyme isoforms SBEII-a and SBEIIb by triggering the RNAi mechanism. Thus, hexaploid bread wheat (Triticum aestivum L.) was transformed with inverted repeat hairpin constructs of the genes encoding SBEII-a and SBEII-b. Transgenic wheat expressing the double strand RNA targeting SBEII- $b$ did not display a significant increase in starch amylose content while RNAi silencing of SBEII- $a$ resulted in an endosperm starch content with more than $70 \%$ amylose. Sestili et al. (2010) followed the same strategy with two cultivars of 
tetraploid durum wheat (T. turgidum L. var. durum). Endosperm specific RNAi silencing of SBEII- $a$ genes in durum wheat led to an increase in amylose content up to $75 \%$.

Rice lines with high amylose content generated by mutational breeding were identified (Yano et al., 1985; Kang et al., 2003; Yang et al., 2006). However none of the mutants displayed an increase in amylose content that is comparable with transgenic high amylose wheat lines. Targeted down-regulation of rice $S B E$ s with an antisense strategy produced transgenic rice lines with an amylose content of $49.2 \%$ whereas the nontransformed variety Teqing had an endosperm amylose content of $22.7 \%$ (Wei et al., 2010). Parallel to increased amylose content, transgenic lines also displayed a significant increase in resistant starch content.

\section{FATTY ACID MODIFICATION}

Fatty acid chain length and degree of saturation are the two most important factors determining the functional, sensory and nutritional value of plant oils (Kinney et al., 2002; Singh et al., 2005). Edible oils contain only five major fatty acids: palmitic acid (C16:0), stearic acid (C18:0), oleic acid (C18:1), linoleic acid (C18:2) and $\alpha$-linolenic acid (C18:3) (Singh et al., 2005). Palmitic and stearic acid are saturated, oleic acid is monounsaturated while linoleic and $\alpha$-linolenic acid are polyunsaturated. In general, oils that are rich in unsaturated fatty acids are considered to be better for the cardiovascular system (Kinney et al.,
2002). One way to increase the amount of unsaturated fatty acids in a plant is to alter the expression of desaturase genes. These genes are responsible for introducing double bonds at specific locations in a fatty acid (Kinney et al., 2002). Transgenic approaches to alter desaturase gene expression have resulted in nutritionally-improved oils from several crops including maize, soybean and oilseed rape (canola, Brassica napus) (Kinney et al., 2002).

Long chain polyunsaturated fatty acids (LC-PUFA), which are normally found only in fish and microalgae oils, are also of particular interest for their health benefits (Singh et al., 2005). LC-PUFA, such as omega-3 oil, can reduce the risk of cardiovascular disease and stroke, reduce symptoms of hypertension and depression and improve brain and retinal health (Kris-Etherton et al., 2002). Although all plants can synthesize the main C18 polyunsaturated fatty acids, linoleic (LA) and $\alpha$-linolenic acid (ALA), only some can synthesize $\gamma$-linolenic acid (GLA, C18:3) and stearidonic acid (SDA, C18:4) and none can synthesize and desaturate longer chain fatty acids (Singh et al., 2005). Therefore, the synthesis of LC-PUFA, such as arachidonic acid (AA, C20:4) and eicosapentaenoic acid (EPA, C20:5), in plants requires the introduction of genes for further elongation and desaturation (Figure 3, Singh et al., 2005).

Using a combination of three genes (one elongase and two desaturases) from an alga, Euglena and a fungus, Qi et al. (2004) engineered a LC-PUFA pathway in Arabidopsis (Figure 3). The transgenic plants produced both omega- 3 and omega- 6

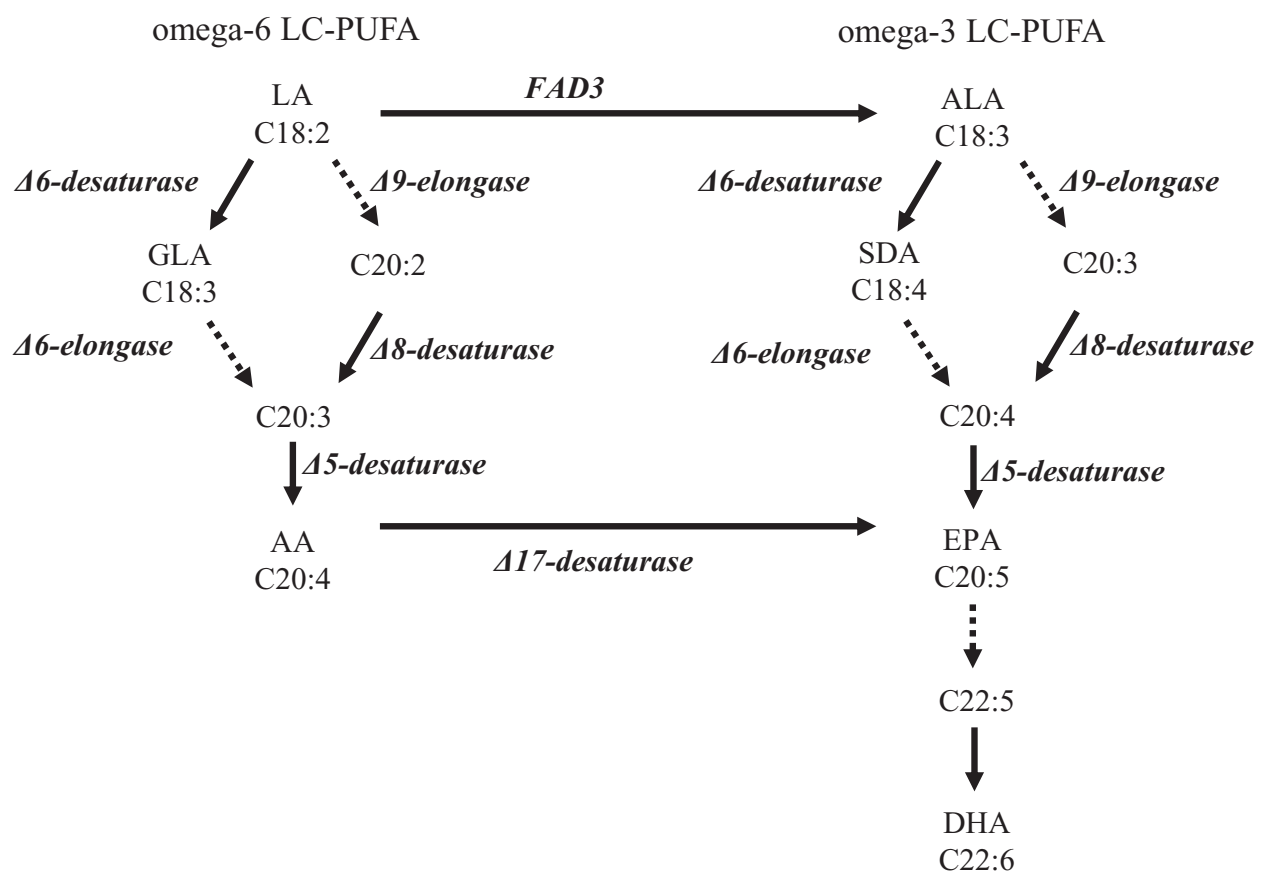

FIG. 3. Aerobic biosynthetic pathways for omega-3 and omega- 6 long chain polyunsaturated fatty acids. Reactions catalyzed by fatty acid desaturases are shown by solid arrows, reactions catalyzed by fatty acid elongases are shown by dotted line arrows. The two pathways are connected by desaturases that can convert LA to ALA and AA to EPA. LA, linoleic acid; GLA, $\gamma$-linolenic acid; AA, arachidonic acid; ALA, $\alpha$-linolenic acid; SDA, stearidonic acid; EPA, eicosapentaenoic acid; DHA, docosahexaenoic acid; $F A D 3$, fatty acid desaturase 3. 
fatty acids including AA and EPA. An alternative LC-PUFA pathway was constructed in linseed (Linum usitatissimum) using three different genes (Abbadi et al., 2004). Seeds of transgenic plants contained $17 \%$ GLA, $11 \%$ SDA, $1 \%$ AA and $0.8 \%$ EPA. The relatively poor synthesis of the longer chain fatty acids (AA and EPA) was thought to be due to problems with transfer of pathway intermediates to the correct substrate pool for further elongation. Therefore, effective alteration may require the introduction of acyl-transferases to move fatty acid acyl groups between the elongation and desaturation pools. Another important factor for fatty acid modification is the choice of target species because different plants have different endogenous metabolic pathways that can facilitate or hinder the engineering of a new or extended pathway (Rawsthorne, 2002). EPA content of $19.6 \%$ was achieved in soybean somatic embryos by expressing the components of the conventional $\Delta 6$-pathway: a $\Delta 6$ desaturase from Saprolegnia diclina or Medicago alpina, a $\Delta 6$ elongase from M. alpina and a $\Delta 5$ desaturase from M. alpina (Kinney et al., 2004). In order to maximize the accumulation of omega-3 LC-PUFAs by converting the omega-6 PUFA metabolites into their omega- 3 counterparts, two additional genes; an Arabidopsis $F A D 3$ and a $S$. diclina $\triangle 17$ desaturase were also expressed. High EPA accumulation with no AA intermediate was attributed to the high efficiency of the $\Delta 17$ desaturase (Kinney et al., 2004). Higher yields obtained with soybean compared to linseed might be attributed to the differences in endogenous lipid metabolism of linseed and soybean (Venegas-Caleron et al., 2010).

Because pathway modification usually involves more than one gene, a variety of seed-specific promoters are also essential to obtain high levels of fatty acid accumulation in seeds without gene silencing (Daniell and Dhingra, 2002). The effects of host plant species, promoters and transgenes on the seed specific production of EPA in Brassica oilseeds were tested (Cheng et al., 2010). The choice of host species had the largest effect on the production of EPA, with the zero-erucic acid Ethiopian mustard (B. carinata) being a superior host than Indian mustard (B. juncea). An average accumulation of $20.4 \%$ EPA in transgenic $B$. carinata seeds was established. Moreover, two novel desaturases: 18-carbon omega-3 desaturase $(C p D e s X)$ from the fungal species Claviceps purpurea and 20-carbon omega-3 desaturase (Pir-w3) from the oomycete Pythium irregulare, proved successful in directing the flux from omega- 6 toward the omega3 pathway and accumulating EPA in transgenic plants. In the same study, the potential of the flax seed-specific conlinin1 promoter was tested against the napin promoter from Brassica napus, and conlinin1 was found to be comparable to but not as effective as the napin promoter. However, the reasonable effectiveness of conlinin 1 makes it a potential seed-specific promoter that should be tested with other species.

\section{VITAMIN AND ANTIOXIDANT CONTENT ENGINEERING}

Vitamin deficiency is a worldwide problem that is associated with numerous health problems (FAO, WFP and IFAD, 2012).
For example, vitamin A deficiency significantly increases the risk of dying from common illnesses like diarrhea, measles and malaria (UNICEF, 2009). Unfortunately, many important cereal and other crops are poor sources of essential vitamins (Hirschi, 2009). As a result, a primary goal of crop biotechnology is the improvement of the vitamin content of staple foods like rice and maize. To date, most of the transgenic manipulations of vitamin and micronutrient content have focused on vitamins $\mathrm{A}, \mathrm{C}$ and $\mathrm{E}$, and folate (a B vitamin).

\section{A. Vitamin A}

In addition to increasing the seriousness of certain diseases, vitamin A deficiency causes blindness (WHO, 2012). It is estimated that 250,000 to 500,000 children worldwide go blind each year due to vitamin A deficiency and half of those children die following the loss of their eye sight (WHO, 2012). Perhaps the best-known example of engineering increased vitamin levels in a crop is "Golden Rice" (Ye et al., 2000). Rice is a staple food in many parts of the world and is usually milled to remove the outer layer leaving a pure white endosperm that lacks provitamin A (Bhullar and Gruissem, 2013). Two different vectors were used to introduce the complete $\beta$-carotene biosynthetic pathway into rice (Ye et al., 2000) (Figure 4). The first vector contained two genes required for carotenoid synthesis: phytoene synthase (psy) from daffodil (Narcissus pseudonarcissus) driven by an endosperm-specific promoter and phytoene desaturase from bacteria driven by the constitutive $35 \mathrm{~S}$ promoter. The other vector contained a lycopene $\beta$-cyclase gene from daffodil driven by an endosperm-specific promoter. Carotenoid production in the endosperm varied for each transgenic line, however, one of the transgenic plants produced $1.6 \mu \mathrm{g}$ of carotenoids per $\mathrm{g}$ of endosperm. Since the development of Golden Rice, it was discovered that replacing the daffodil psy gene with one from maize gave much higher levels of carotenoids up to $35 \mu \mathrm{g} / \mathrm{g}$ (Paine et al., 2005).

In other species, modification of provitamin A content was simpler. For example, in oilseed rape, increased levels of $\beta$ carotene in the seed was achieved by overexpression of a single gene, phytoene synthase (Shewmaker et al., 1999). Transgenic plants had 50-fold more carotenoids than control plants with a $\beta: \alpha$-carotene ratio of $2: 1$. When bacterial phytoene desaturase and lycopene cyclase were co-expressed with phytoene synthase, $\beta: \alpha$-carotene ratio reached 3:1 (Ravanello et al., 2003). Suppressing epsilon cyclization of lycopene in order to direct the metabolic flux towards $\beta$ - $\beta$-carotenoids resulted in the increased accumulation of $\beta$-carotene and downstream products of the $\beta$-branch in transgenic canola seeds (Yu et al., 2008). Seven key enzymes of bacterial origin that are involved in ketocarotenoid biosynthesis were introduced to canola plants in order to establish elevated total carotenoid accumulation and ketocarotenoid production (Fujisawa et al., 2009). Ketocarotenoids are potent antioxidants but their production is rare in higher plants due to the absence of a $\beta$-carotene ketolase. Total seed carotenoid content of transgenic lines was 19- to 30 -fold higher than that of control plants with $\beta$-carotene 


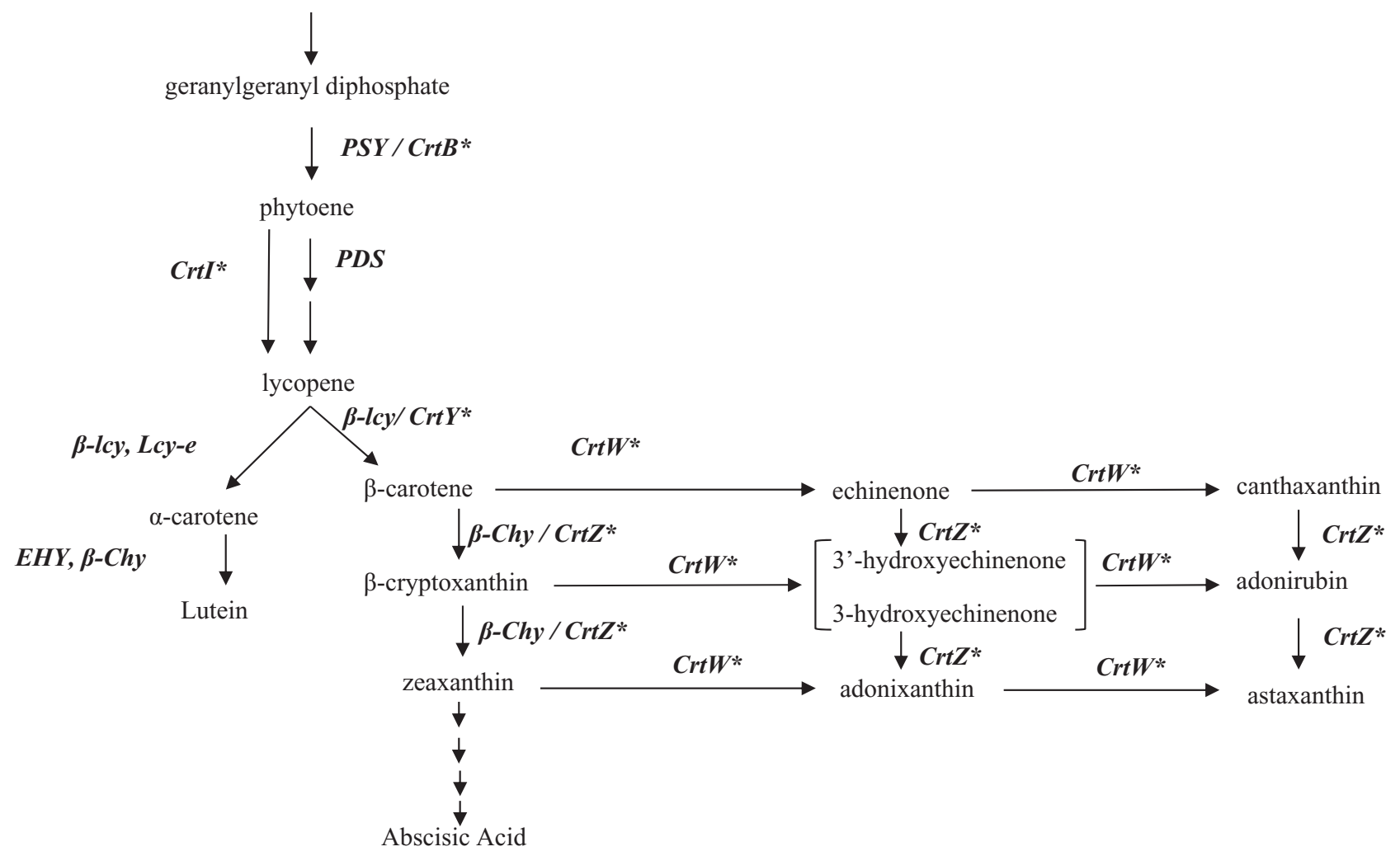

FIG. 4. Schematic plant carotenoid biosynthesis pathway including possible routes for ketocarotenoid synthesis from $\beta$-carotene. Proposed bacterial counterparts of the plant enzymes are indicated with stars. PSY, phytoene synthase; PDS, phytoene desaturase; $\beta$-lcy, lycopene $\beta$-cyclase; $L c y-e$, lycopene $\varepsilon$-cyclase; $E H Y$, $\varepsilon$-carotene hydroxylase; $\beta$-Chy, $\beta$-carotene hydroxylase; $\mathrm{CrtB}$, bacterial phytoene synthase; $\mathrm{CrtI}$, bacterial phytoene desaturase / carotene isomerase; $\mathrm{CrtY}$, bacterial lycopene $\beta$-cyclase; $\operatorname{CrtZ}$, bacterial $\beta$-carotene hydroxylase; $\operatorname{Crt} W$, bacterial $\beta$-carotene ketolase.

being the predominant carotenoid. Lutein and phytoene levels were also elevated accompanied by the accumulation of ketocarotenoids echinenone and canthaxanthin at significant levels (Fujisawa et al., 2009).

In tomato, introduction of a bacterial phytoene desaturase gene did not cause an increase in total carotenoids but did result in a three-fold increase in $\beta$-carotene (Romer et al., 2000). Tomato cultivar Moneymaker was transformed with Arabidopsis lycopene $\beta$-cyclase ( $\beta$-lcy) under the control of the tomato phytoene desaturase promoter whose activity is up-regulated during ripening (Rosati et al., 2000). Transgenic tomatoes displayed a range of phenotypes from red to orange with the most affected line having seven-fold higher $\beta$-carotene content with respect to the wild-type control. Total carotenoid content was also elevated in most of the transgenic lines. In order to accumulate $\beta$-cyclization products downstream of the lycopene pool, the cultivar Moneymaker was transformed with $\beta$-lcy and $\beta$ carotene hydroxylase ( $\beta$-Chy) under the control of the phytoene desaturase promoter (Dharmapuri et al., 2002). Transgenic lines accumulated up to $24 \mu \mathrm{g} / \mathrm{g}$ fresh weight of $\beta$-cryptoxanthin and zeaxanthin, which were not detectable in the parental line. Wild type fruits accumulated $5 \mu \mathrm{g} / \mathrm{g}$ fresh weight of $\beta$-carotene while as much as $63 \mu \mathrm{g} / \mathrm{g}$ fresh weight was measured in the trans- genic lines. Fraser et al. (2002) transformed the cultivar Ailsa Craig with a bacterial phytoene synthase under the control of the tomato polygalacturonase $(P G)$ promoter in order to establish ripening-specific expression. Primary transformants expressing the bacterial transgene had two- to four-fold higher total carotenoids with increased phytoene, lycopene and $\beta$-carotene levels. Constitutive expression of tomato lycopene $\beta$-cyclase cDNA resulted in individual tomato fruit that could provide the Recommended Daily Allowance (RDA) of $\beta$-carotene for three adults (D'Ambrosio et al., 2004). These transgenic tomatoes (HighCaro) displayed an intense orange color due to high $\beta$-cyclase activity which resulted in the accumulation of $\beta$ carotene instead of lycopene. Plastid engineering also proved successful in accumulating high levels of $\beta$-carotene in tomato fruits (Apel and Bock, 2009). Transplastomic tomatoes expressing $\beta$-cyclase from daffodil (Narcissus pseudonarcissus) accumulated nearly $1 \mathrm{mg} / \mathrm{g}$ DW (dry weight) of $\beta$-carotene with a $50 \%$ increase in total carotenoid content.

Although a staple crop, potato is significantly poor in $\beta$ carotene (Breithaupt and Bamedi, 2002). However, metabolic engineering efforts to accumulate high levels of $\beta$-carotene in potato tubers proved successful (Ducreux et al., 2005; Diretto et al., 2006; Diretto et al., 2007a \& b; Lu et al., 2006; 
Lopez et al., 2008). Two potato cultivars were selected for work to increase the carotenoid content of potato tubers: Solanum tuberosum L. cultivar Desiree, which typically accumulates $5.6 \mu \mathrm{g} / \mathrm{g}$ DW carotenoids with negligible $\beta$-carotene content and Solanum phureja L. cv. Mayan Gold, which typically accumulates $20 \mu \mathrm{g} / \mathrm{g}$ DW carotenoids (Ducreux et al., 2005). Both cultivars were transformed with the $\mathrm{crtB}$ gene (for phytoene synthase) from Erwinia uredovora. Tuber specific expression of the transgene under the control of the patatin promoter resulted in the accumulation of $35 \mu \mathrm{g} / \mathrm{g}$ DW total carotenoids and $11 \mu \mathrm{g} / \mathrm{DW} \beta$-carotene in developing tubers of the cultivar Desiree. In addition, transgenic Mayan Gold tubers displayed a high level of carotenoid accumulation with $78 \mu \mathrm{g} / \mathrm{g}$ DW (Ducreux et al., 2005). In another study with a similar objective, the gene encoding Lcy-e was targeted with a tuberspecific antisense construct in order to suppress epsilon cyclization of lycopene and direct the flux towards $\beta$ - $\beta$-carotenoid branch (Diretto et al., 2006). Results indicated a tuber-specific increase in the accumulation of $\beta$-carotene (up to 14-fold) and $\beta$ - $\beta$-carotenoids (up to 2.5 -fold) without a decrease in the accumulation of lutein. When the $\beta$-carotene hydroxylation step of the $\beta$ - $\beta$-carotenoid branch was targeted by tuber-specific antisense silencing of the hydroxylases $C H Y 1$ and $C H Y 2$, a 38-fold increase in tuber $\beta$-carotene content was achieved (Diretto et al., 2007a). A promising genetic tool for carotenoid biofortification is the novel Orange (Or) mutation isolated from cauliflower (Brassica oleracea var botrytis) (Zhou et al., 2008). The mutant orange phenotype is due to the accumulation of carotenoids caused by the differentiation of proplastids into chromoplasts. The mutant phenotype was also confirmed in potato tubers carrying the $\mathrm{Or}$ transgene (Lu et al., 2006; Lopez et al., 2008). Potato cultivar Desiree was transformed with three genes of bacterial origin that encode phytoene synthase $(C r t B)$, phytoene desaturase $(\mathrm{CrtI})$ and lycopene beta-cyclase $(\mathrm{Cr} t \mathrm{Y})$ from Erwinia uredovora, under the control of the patatin promoter (Diretto et al., 2007b). Potato tubers transformed with the bacterial mini pathway accumulated $47 \mu \mathrm{g} / \mathrm{g}$ DW $\beta$-carotene, which corresponds to $50 \%$ of the RDA if $250 \mathrm{~g}$ of fresh weight is consumed.

With conventional breeding, a few maize lines with relatively high provitamin A content were developed (Harjes et al., 2008). However, kernels of traditional yellow maize varieties do not exhibit sufficient provitamin A levels (Aluru et al., 2008). In order to enhance the provitamin A content of maize, the Hi-II white maize variety was transformed with bacterial $c r t B$ and $\mathrm{CrtI}$ driven by an endosperm specific super $\gamma$-zein promoter (Aluru et al., 2008). Resulting transgenic kernels displayed up to 34-fold increased total carotenoids accompanied by elevated levels of $\beta$-carotene. Naqvi et al. (2009) engineered three metabolic pathways simultaneously to achieve elevated levels of $\beta$-carotene, ascorbate and folate in transgenic maize seeds. Expression of the two transgenes, the Zea mays phytoene synthase ( $p s y l)$ cDNA under the control of wheat LMW glutenin promoter and the Pantoea ananatis crtI gene under the control of the barley D-hordein promoter, gave rise to the accumulation of up to 112-fold higher total carotenoids and up to 169-fold higher $\beta$-carotene (approx. $60 \mu \mathrm{g} / \mathrm{g} \mathrm{DW}$ ) in maize endosperm.

Hexaploid common wheat (Triticum aestivum L.) is not a rich source of carotenoids, and grains typically have lutein and zeaxanthin as the main components of carotenoid content (Humpheries and Khachik, 2003). Cong et al. (2009) introduced maize phytoene synthase (maize $y l$ ) and bacterial $\mathrm{CrtI}$ to the elite variety EM12 under the control of the glutenin subunit $1 D x 5$ and $C a M V 35 S$ promoters, respectively. Besides the light yellow color observed, an increase of up to 10.8-fold was measured for endosperm carotenoid accumulation compared to the non-transgenic controls.

Cassava was also targeted for improved provitamin A accumulation (Sayre et al., 2011). When the bacterial $c r t B$ was expressed under the control of the storage root specific patatin promoter, a 10- to 20-fold increase in total carotenoid content was achieved. Co-expressing 1-deoxyxylulose-5-phosphate synthase $(D X S)$ with $c r t B$ for increased geranylgeranyl diphosphate (GGDP) production proved more effective and yielded 15- to 30-fold higher total carotenoid content compared to wild type roots.

\section{B. Vitamin $\mathrm{E}$}

Vitamin $\mathrm{E}$ is also an important micronutrient for human health. Increased intake of vitamin $E$ is linked to decreased risk of cardiovascular disease and cancer (Bramley et al., 2000). Vitamin $\mathrm{E}$ also helps the immune system and prevents or slows several degenerative diseases. Vitamin $\mathrm{E}$ actually consists of a group of eight related compounds: the $\alpha, \beta, \gamma$, and $\delta$-tocopherols and the $\alpha, \beta, \gamma$ and $\delta$-tocotrienols (Rocheford et al., 2002). The vitamin $\mathrm{E}$ activity of each of these isoforms varies. A methylated form of $\alpha$-tocopherol has the highest activity while $\gamma$-tocopherol has only one tenth the activity of $\alpha$-tocopherol (Van Eenennaam et al., 2003). Among tocotrienol isomers, antioxidant activity of the $\alpha$ isomer is considered to be the highest (Zhang et al., 2012). The protective function of the tocols is due to their roles as antioxidants. In cell membranes, tocopherols protect polyunsaturated fatty acids from oxidative damage by free radicals. Excessive free radical production can cause tissue damage, which is thought to be related to cardiovascular disease, cancer and neurological diseases (Bramley et al., 2000). As only photosynthetic organisms synthesize tocopherols, humans should receive this essential micronutrient in their diet (Naqvi et al., 2011).

Soybean oil is one of the most commonly used food oils (Van Eenennaam et al., 2003). As tocochromannols (tocopherols and tocotrienols) are lipid soluble compounds, soybean oil is a good target for the improvement of $\alpha$-tocopherol content and vitamin $\mathrm{E}$ activity. In an early example of vitamin $\mathrm{E}$ engineering, a 2-methyl-6-phytyl benzoquinol methyltransferase from Arabidopsis was expressed in soybean seeds (Figure 5, Van Eenennaam et al., 2003). Expression of this gene decreased $\delta$ tocopherol from $20 \%$ to $2 \%$. The gene was also co-expressed 


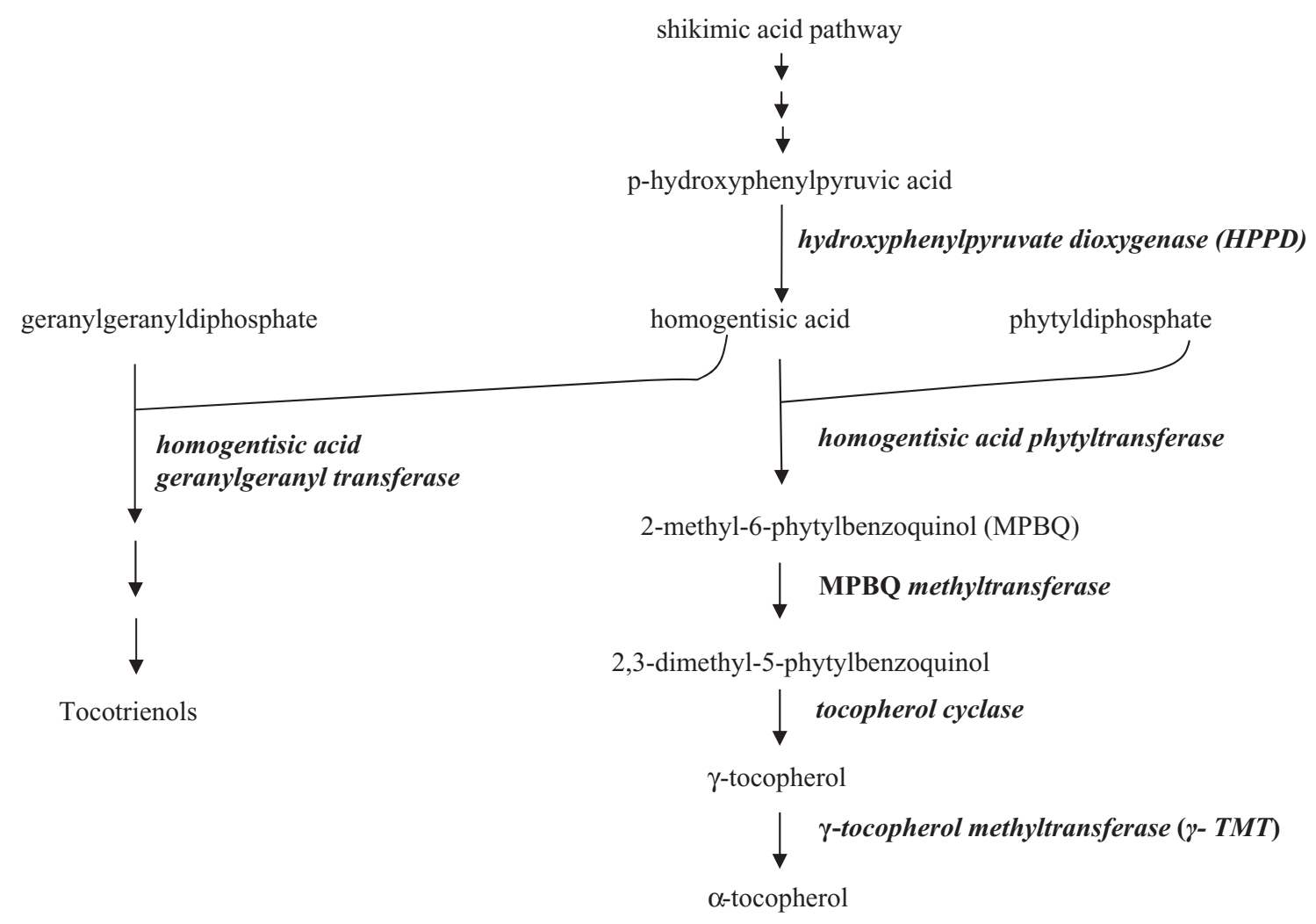

FIG. 5. Tocopherol and tocotrienol biosynthetic pathways.

with $\gamma$-tocopherol methyltransferase. Seeds of these transgenic plants had $>95 \% \alpha$-tocopherol as compared to $10 \%$ in untransformed seeds. This dramatic increase in $\alpha$-tocopherol levels was accompanied by a five-fold increase in seed vitamin $\mathrm{E}$ activity. Up to 15-fold increase in total tocochromanols (tocopherols and tocotrienols) in transgenic soybean was achieved through the seed-specific expression of the limiting pathway enzymes (Karunanandaa et al., 2005). In the resulting transgenic seeds, up to $94 \%$ of the total tocochromanol content was accumulated as tocotrienols. However, $\mathrm{F}_{2}$ progeny of the cross between the transgenic high tocotrienol and transgenic high $\alpha$-tocopherol lines displayed up to 11 -fold higher seed vitamin E activity compared to wild type. In another example of vitamin E engineering in soybean, Tavva et al. (2007) overexpressed the Perilla frutescens tocopherol methyl transferase $(\gamma-T M T)$ gene in soybean seeds, which resulted in increased conversion of $\gamma$-tocopherol and $\delta$-tocopherol to $\alpha$-tocopherol and $\beta$-tocopherol, respectively. Transgenic $\mathrm{T}_{2}$ seeds had 10.4fold increased $\alpha$-tocopherol content and 14.9-fold increased $\beta$ tocopherol content with 4.8 -fold higher vitamin $\mathrm{E}$ activity. Hydroxyphenylpyruvate dioxygenase (HPPD) catalyzes the first committed step in vitamin E biosynthesis (Raclaru et al., 2006). A chimeric HPPD gene (a combination of Synechocystis and Homo sapiens ORFs) was overexpressed in rapeseed (Brassica napus) simultaneously with Arabidopsis homogentisate phytyltransferase (HPT) and tocopherol cyclase (TC) in a seed-specific manner. A 2.4-fold increase in seed oil tocopherol content was measured as a result of the co-expression of these three transgenes.

In addition to oilseed crops, there are also efforts concentrated on engineering the vitamin $\mathrm{E}$ content of staple crops (Naqvi et al., 2011; Farre et al., 2012; Zhang et al., 2012). In a recent study that aimed to improve the tocopherol content of maize, a South African elite maize line was transformed with two cDNAs from Arabidopsis that encode enzymes involved in tocopherol biosynthesis (Naqvi et al., 2011). Three transgenic lines expressing Arabidopsis $H P P D$ and $M P B Q M T$ (MPBQ methyltransferase that adds a methyl group to MBPQ) under the control of the corn ubiquitin-1 promoter displayed higher levels of $\gamma$-tocopherol with respect to wild type. The transgenic line with the highest $\gamma$-tocopherol content accumulated up to $8.8 \mu \mathrm{g} / \mathrm{g} \mathrm{DW}$, an amount that is three times higher than that of wild type. However, no elevation in the levels of other isoforms, including the most beneficial isoform $\alpha$-tocopherol, could be achieved, indicating the requirement for $\gamma$-TMT activity in order to yield elevated levels of the $\alpha$-isomer. Transgenic rice overexpressing the Arabidopsis HPPD under the control of the maize constitutive ubiquitin1 promoter displayed only a slight increase in tocochromanol content due to the increased production of tocotrienols (Farre et al., 2012). However, transgenic rice grains had a significantly increased $\alpha: \gamma$ tocopherol ratio, indicating increased vitamin E activity. The shift from the $\gamma$ to 
$\alpha$ isoform was attributed to a possible positive feedback of $\gamma$ TMT activity. The Arabidopsis $\gamma$-TMT gene was expressed in rice constitutively and in an endosperm specific manner (Zhang et al., 2012). In both cases, but especially in the case of constitutive expression, the shift from $\gamma$ and $\delta$ isoforms towards $\alpha$ tocotrienol was significant. Although an increase in the $\alpha: \gamma$ ratio was observed in transgenic rice endosperm, the altered relative abundance of isoforms did not lead to an elevation in $\alpha$-tocopherol content.

\section{Vitamin C}

Like vitamin E, vitamin C (ascorbic acid) is one of the body's most important antioxidants (Davey et al., 2000). In addition to its ability to neutralize free radicals and reactive oxygen species that can damage DNA, membranes and tissues, vitamin $\mathrm{C}$ acts as an enzyme cofactor and is needed for the synthesis of collagen, carnitine and neurotransmitters. Vitamin $C$ is also required to maintain a healthy immune system and is used to regenerate $\alpha$-tocopherol (Chen et al., 2003). As a consequence of a mutation event in the enzyme catalyzing the last step of vitamin $\mathrm{C}$ biosynthesis (L-gulono- $\gamma$-lactone oxidase), humans cannot synthesize vitamin $C$, and plants constitute the major source of this essential vitamin in the diet (Lachapelle and Drouin, 2011).

Although little is known about the ascorbic acid biosynthetic pathway in plants, modification of vitamin $\mathrm{C}$ content in crops was achieved in several ways. In the first example, a rat Lgulono- $\gamma$-lactone oxidase gene was transformed into lettuce to obtain a seven-fold increase in vitamin C (Jain and Nessler, 2000). The rat gene was also constitutively expressed in potato in a recent study, giving rise to $40 \%$ higher ascorbate accumulation and increased abiotic stress tolerance (Hemavathi et al., 2010). Because consumption of food containing a rat gene product may be objectionable to some consumers, most efforts have focused on exploring the use of plant genes to improve vitamin C content. Overexpression of a D-galacturonic acid reductase from strawberry was used to increase vitamin C levels in Arabidopsis by two- to three-fold (Agius et al., 2003). This enzyme reduces D-galacturonic acid to L-galactonic acid in the pathway for ascorbic acid biosynthesis via uronic acids. Its overexpression in potato gave rise to a two-fold increase in tuber ascorbate content, accompanied by increased drought, salt and oxidative stress tolerance with respect to wild type plants (Hemavathi et al., 2009).

Ascorbate recycling is another target of genetic engineering towards vitamin $\mathrm{C}$ biofortified crops. Dehydroascorbate reductase (DHAR) catalyzes the reaction that recycles vitamin $\mathrm{C}$ by converting oxidized ascorbic acid back to its non-oxidized form (Chen et al., 2003). Chen et al. (2003) doubled vitamin $\mathrm{C}$ levels in maize kernels by the overexpression of a DHAR gene from wheat (Figure 6). Following a similar strategy, a six-fold increase (approx. $110 \mu \mathrm{g} / \mathrm{g} \mathrm{DW}$ ) in ascorbate content was achieved by expressing a rice DHAR cDNA in maize endosperm (Naqvi et al., 2009). Increased folate and $\beta$-carotene levels were also achieved in the same study. Qin et al. (2011) transformed potato with its native cytosolic and chloroplastic targeted DHAR cDNAs, each under the control of the CaMV $35 \mathrm{~S}$ promoter. Overexpression of cytosol-targeted DHAR led to increased ascorbate content in both tubers and leaves while overexpressing the chloroplastic enzyme only affected leaf ascorbate content. cDNAs encoding cytosol-targeted ascorbate recycling enzymes DHAR and MDHAR (monodehydroascorbate reductase) were cloned and overexpressed in tomato (Haroldsen et al., 2011). Overexpression of the native DHAR resulted in a 1.6-fold increase in the ascorbic acid content of mature green and red ripe fruits under low light conditions while MDHAR overexpressed lines grown under the same conditions had decreased ascorbic acid content in their mature green fruits.

An RNAi strategy was recently employed in order to obtain higher levels of vitamin $\mathrm{C}$ by modulating the expression of enzymes related to ascorbate metabolism (Zhang et al., 2011a; 2011b). AO (ascorbate oxidase) and APX (ascorbate peroxidase) are the enzymes that oxidize ascorbic acid to MDHA (monodehydroascorbate) in plants. Zhang et al. (2011a; 2011b) used RNAi to down-regulate the expression of both enzymes in tomato. RNAi suppression of $A O$ expression resulted in up to $155 \%$ improvement of fruit ascorbate content (Zhang et al., 2011a). Similarly, RNAi suppression of a mitochondrial $A P X$ resulted in 1.4- to 2.2-fold increases in fruit ascorbate content compared to wild type control. Successful down-regulation of the enzyme's expression and activity was attributed to the relatively high identity in conserved regions of the tomato $A P X$ gene family that possibly gave rise to the suppression of a number of other members as well (Zhang et al., 2011b).

\section{Folate}

Folate, also known as vitamin B9, is a B vitamin that is essential for preventing birth defects and decreasing the risk of certain types of anemia, cardiovascular disease and cancer (Hossain et al., 2004). Humans are unable to synthesize folates, so they should receive these essential micronutrients within their daily diet (Basset et al., 2005). Green leafy vegetables and citrus fruits contain high levels of folate; however, cereal, root and tuber crops contain very low levels (Bekaert et al., 2008). Folates are tripartite molecules, and pteridine, paminobenzoate (PABA) and glutamate constitute the precursors for folate synthesis (Basset et al., 2005). In the first report that described genetic engineering of folates in plants, a gene for a rate-determining step of folate synthesis, GTP cyclohydrolase1, was cloned from E. coli and introduced into Arabidopsis (Hossain et al., 2004). Transgenic plants had a 1,250-fold increase in pterins, the substrate for folate synthesis, and a twoto four-fold increase in folates. In a similar study, a codon optimized synthetic mammalian GTP cyclohydrolase I (GCHI) was expressed in ripening tomato fruits in order to enhance pteridine synthesis (de la Garza et al., 2004) (Figure 7). The rationale for the choice of transgene was the decline in pteridine synthesis during ripening, which is presumably a limiting factor for the accumulation of folates in mature tomato fruit. Average 


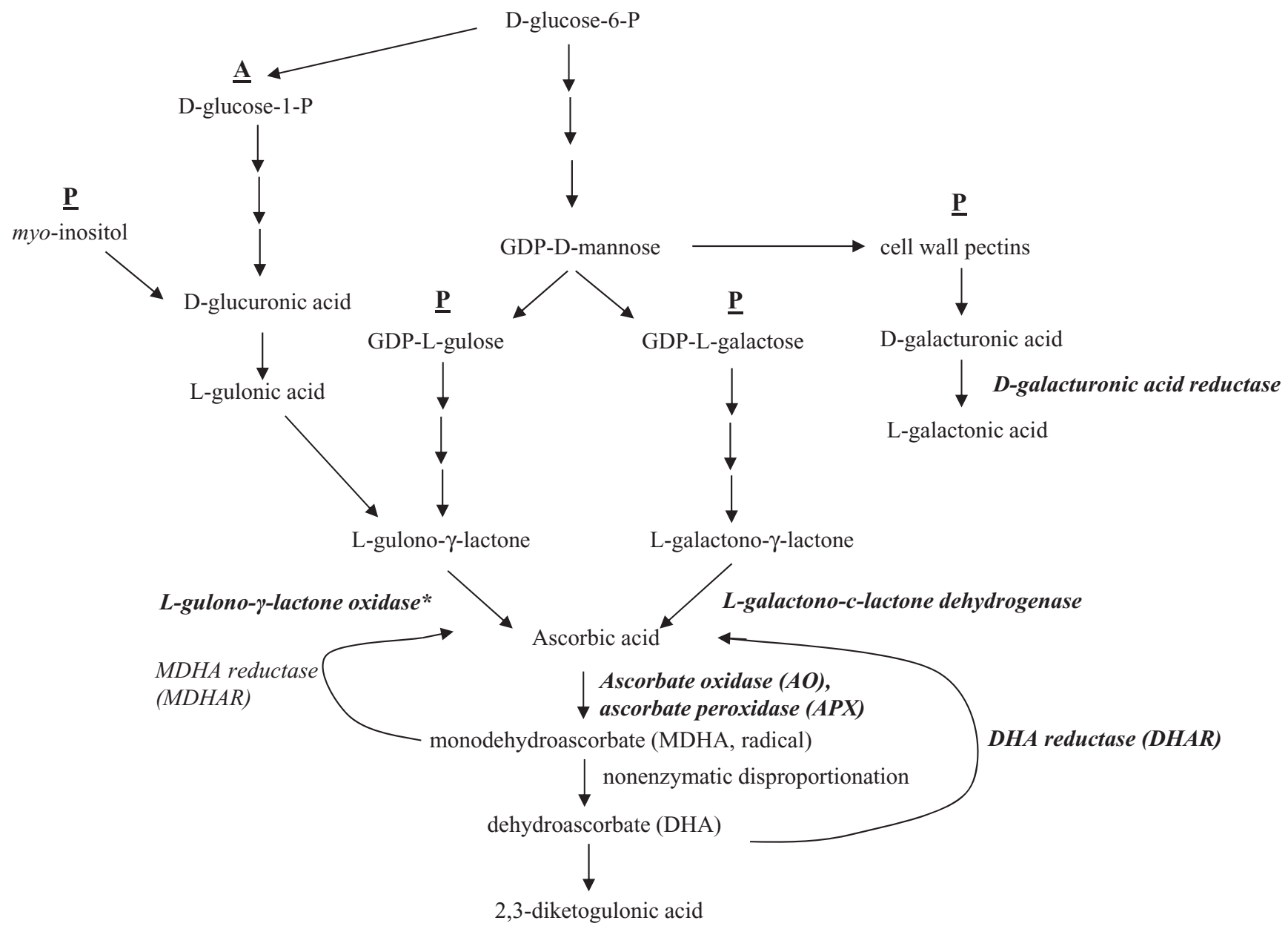

FIG. 6. Schematic pathway for ascorbic acid biosynthesis and recycling. Pathways indicated with P are proposed plant pathways. Pathway A is the proposed animal pathway. Enzyme indicated with star is the ascorbic acid biosynthesis enzyme absent in humans.

increase in fruit folate content of the resultant transgenic plants was two-fold with up to 140 -fold increased pteridine content. As only a modest increase in folate content could be established by upregulating the pteridine branch of folate biosynthesis, the PABA branch became a complementary target for upregulation in further studies. Tomatoes that supply the recommended daily allowance of folate in a 100 gr serving were produced by combining enhanced pteridine and PABA production in a single plant (de la Garza et al., 2007). In order to upregulate PABA synthesis, the tomato variety MicroTom was transformed with the aminodeoxychorismate synthase $(A D C S)$ from Arabidopsis under the control of the ripening specific E8 promoter (de la Garza et al., 2004). Transgenic plants were used to pollinate plants carrying the GCHI transgene. Double transgenic fruits were reported to accumulate $840 \mu \mathrm{g} / 100 \mathrm{~g}$ folate, an amount that is more than the recommended dietary allowance for pregnant women (de la Garza et al., 2007).

As a staple crop, rice has also been a target for vitamin B9 improvement (Storozhenko et al., 2007; Gillies et al., 2008; Naqvi et al., 2009). Following a similar strategy as de la
Garza et al. (2007), Storozhenko et al. (2007) overexpressed Arabidopsis genes for the PABA and pterin branches in rice and achieved significantly elevated levels of folate, with the resulting transgenic plants containing up to four times the adult daily requirement/100 g of polished grains. Gillies et al. (2008) expressed the bifunctional enzyme, 6-hydroxymethyl7,8 dihydropterin pyrophosphokinase/7,8-dihydropteroate synthase (HPPK/DHPS) which acts at a central point in the folate pathway (Figure 7), in order to improve folate production in transgenic rice grains. However, expression of the wheat enzyme driven by the maize ubiquitin promoter resulted in only a modest increase (up to $75 \%$ ) in folate production in grains and leaves. Naqvi et al. (2009) engineered three distinct metabolic pathways simultaneously in order to improve folate, ascorbate and vitamin A biosynthesis in maize endosperm. The folE gene, encoding GCHI in E. coli, was expressed in maize endosperm under the control of the barley D-hordein promoter. Endosperm-specific expression of the E. coli folE gave rise to a two-fold increase in folate accumulation in transgenic maize endosperm. 


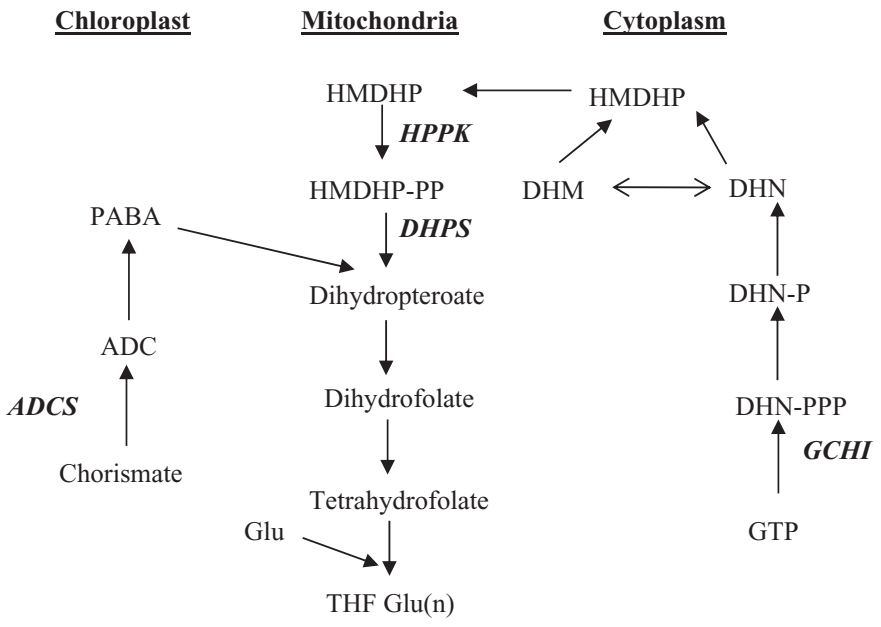

FIG. 7. Schematic pathway for folate biosynthesis in plants. ADC, aminodeoxychorismate; PABA, para-aminobenzoic acid; HMDHP, hydroxymethldihydropterin; THF(Glu)n, tetrahydrofolate glutamated; DHN, dihydroneopterin; DHM, dihydromonapterin; $A D C S$, Aminodeoxychorismate synthase; GCHI, GTP cyclohydrolase-1; HPPK, 6-hydroxymethyl-7,8 dihydropterin pyrophosphokinase; DHPS, 7,8-dihydropteroate synthase.

The genetic engineering approaches described above all involved the manipulation of folate biosynthesis. However, hydrolysis of the folate polyglutamyl tail represents an alternative target for manipulation towards folate biofortification of plants (Akhtar et al., 2010). The polyglutamyl tail consists of up to eight glutamate residues and is believed to directly affect the activity and stability of folate and the activity of the vacuolar enzyme, $\gamma$-glutamyl hydrolase $(\mathrm{GGH})$ removes the polyglutamyl tail. In a study that aimed to deduce the function of GGH, knockdown of the enzyme resulted in an approximately $30 \%$ increase in folate content in Arabidopsis leaves, promising potential for the manipulation of the folate polyglutamyl tail to obtain high levels of folate in food crops (Akhtar et al., 2010).

\section{E. Other Antioxidants}

As previously mentioned, antioxidants are compounds that neutralize free radicals and reactive oxygen species (Blokhina et al., 2003). As a result, these compounds help to protect DNA, lipids, proteins, membranes and tissues from damage caused by oxidative stress. Increased consumption of fruits and vegetables rich in antioxidants can decrease the risk of cancer, cardiovascular and neurodegenerative diseases and delay aging (Deshpande et al., 1996; Bazzano et al., 2002; De PasqualTeresa and Sanchez-Ballesta, 2008; Zhu et al., 2012). The most prevalent and important plant-derived antioxidants include vitamins $\mathrm{C}$ and $\mathrm{E}$; carotenoids like $\beta$-carotene (provitamin $\mathrm{A}$ ) and lycopene; and phenolic compounds (Tucker, 2003). In addition to the previously described work with provitamin A and vitamins $\mathrm{C}$ and $\mathrm{E}$, success was achieved with genetic modification of other antioxidants in plants.

Lycopene is a strong antioxidant that gives ripe tomatoes their red color and is a product of the carotenoid synthetic pathway
(Takeoka et al., 2001). In work to improve the carotenoid and lycopene content of tomato, a phytoene synthase gene from $\mathrm{Er}$ winia uredovora was overexpressed in transgenic plants (Fraser et al., 2002). The transformants had a two- to four-fold increase in fruit carotenoids with 1.8- to 2.2-fold increases in lycopene and $\beta$-carotene, respectively. Overexpression of a yeast S-adenosyl methionine decarboxylase gene was also shown to increase lycopene levels in tomato (Mehta et al., 2002). This was an unexpected result as the researchers were only attempting to alter polyamine synthesis by expression of the yeast gene. This example highlights the complexity and potential interrelatedness of biosynthetic pathways that can complicate the engineering of nutritional quality. The xanthophyll class of carotenoids represents an important class of compounds with antioxidant properties (Sies et al., 1992). Xanthophyll content was engineered in tomato through the overexpression of Arabidopsis lycopene $\beta$-cyclase $(\beta$-lcy) and pepper $\beta$-carotene hydroxylase $(\beta$-Chy) genes under the control of the fruit-specific tomato phytoene desaturase promoter (Dharmapuri et al., 2002). Due to the enhancement of cyclization of the lycopene pool, up to $24 \mu \mathrm{g} / \mathrm{g}$ fresh weight of $\beta$-cryptoxanthin and zeaxanthin accumulated in transgenic tomatoes. When it is considered that the levels of those compounds are below the limit of detection in wild type fruits, the results represent a significant achievement in xanthophyll biofortification of tomato.

Keto-carotenoids are a class of carotenoids that have at least one keto group (Ralley et al., 2004). These pigments have high antioxidant activity (Ahn et al., 2012). Among keto-carotenoids, astaxanthin (3,3'-dihydroxy- $\beta, \beta$-carotene-4,4'-dione) was reported to have antioxidant activity several times higher than $\beta$-carotene and $\alpha$-tocopherol (Park et al., 2010). Astaxanthin is of special interest because there is increasing evidence of the benefits of this pigment for human health (Jayaraj et al., 2008). This potent antioxidant was reported to prevent cardiovascular disease, enhance the immune system, prevent cataracts and tissue damage from UV radiation and have antibacterial and anticancer properties. The carapace of crustaceans and the flesh of salmon and trout accumulate the pigment in high amounts (Park et al., 2010). However, with the exception of Adonis aestivalis, whose blood-red petals accumulate the pigment in significant quantities (Cunningham and Gantt, 2005), most higher plants lack the ability to synthesize astaxanthin and other keto-carotenoids because they do not have $\beta$-carotene ketolase (Ralley et al., 2004). Astaxanthin production was reported for a few other plant species, none of which accumulate the bright red pigment in comparable levels with the petals of the ornamental Adonis. The pigment is used as a natural colorant, feed additive in aquaculture and poultry farming, and research investigating the effects of astaxanthin on human health suggests that this carotenoid is an essential dietary supplement (Jayaraj et al., 2008). With the aim of producing this valuable ketocarotenoid in plants, transgenic approaches including plastid transformation were carried out (Ralley et al., 2004). Although not yet applicable for most crop plant species, plastid transformation 
promises many advantages over nuclear transformation such as high expression level of the transgene due to the high copy number of the plastid genome and no requirement for a transit peptide to target transgene expression to the plastid (Maliga, 2004). Hasunuma et al. (2008) applied chloroplast transformation for the production of astaxanthin in tobacco leaves. In the study, $\beta$-carotene ketolase $(\mathrm{Cr} t W)$ and $\beta$-carotene hydroxylase (CrtZ) genes from the marine bacterium Brevundimonas sp. were used to transform tobacco chloroplasts by homologous recombination. The transplastomic approach proved successful, accumulating $5.44 \mathrm{mg} / \mathrm{g}$ DW astaxanthin and 2.1-fold higher total carotenoids than control plants.

Carrot storage roots represent an appropriate target to engineer for keto-carotenoid accumulation as they naturally accumulate high levels of $\alpha$ and $\beta$-carotene (Jayaraj et al., 2008). Up to $2400 \mu \mathrm{g} / \mathrm{g}$ root dry weight of ketocarotenoids accumulated in roots as a result of engineering the ketocarotenoid biosynthetic pathway in carrot. Double CaMV 35S, Arabidopsis ubiquitin and Agrobacterium rhizogenes RolD promoters, all of which provide high expression in transgenic roots, were used to drive the expression of $C r t W$ from Haematococcus pluvialis. The enzyme was targeted to plastids with the pea Rubisco small sub-unit transit peptide. Results of this work indicated that astaxanthin, adonirubin, and canthaxanthin are the predominant ketocarotenoids in the ketocarotenoid pool. Astaxanthin content of an average transgenic carrot reached $9 \mathrm{mg}$, an amount that is higher than the daily recommended dose of $5 \mathrm{mg}$. However, transgenic roots accumulated only $34 \%$ of the $\beta$-carotene content of wild type carrots due to the hydroxylation of the native $\beta$-carotene pool (Jayaraj et al., 2008). Results of recent work to produce ketocarotenoids in carrot roots were inconsistent with the previous work in terms of altered $\beta$-carotene accumulation (Ahn et al., 2012). Ahn et al. (2012) used the same enzyme, $\beta$-carotene ketolase from Haematococcus pluvialis; however; they used the sweet potato $i b A G P 1$ promoter to drive the expression of the $C r t W$ cDNA and the $i b A G P l$ transit peptide to target the enzyme into plastids. Astaxanthin accumulation was visible to the naked eye as a reddish orange color of the roots with $17.2 \mu \mathrm{g} / \mathrm{g}$ DW of the pigment measured in the highest accumulating line. In addition, a 2.4-fold increase in the level of $\beta$-carotene was detected in the transgenic roots. Although the same algal enzyme was used to transform the plants in both studies, the $\beta$-carotene pool was presumably consumed as substrate in the former study. Ahn et al. (2012) suggested that sequence dissimilarity between their algal $\beta$-carotene ketolase cDNA and the gene used by Jayaraj et al. (2008) may have given rise to differential substrate preference. Another explanation provided by the authors was the differences in the expression systems that were used in the two studies.

Flavonoids are a large family of polyphenolic compounds that are also powerful antioxidants (Bovy et al., 2002). There are more than 4,000 different flavonoids including chalcones, isoflavonoids, flavanones, flavonols, and anthocyanins (Figure 8). Although tomato is rich in other antioxidants like vitamin $\mathrm{C}$ and lycopene, it contains only small amounts of flavonoids and these are limited to the peel (Muir et al., 2001). Genes that act in flavonoid synthesis are expressed at relatively low levels in fruit flesh (Muir et al., 2001; Bovy et al., 2002; Schijlen et al., 2006). In early work to increase flavonol levels in the flesh of tomato fruit, a petunia chalcone isomerase gene was
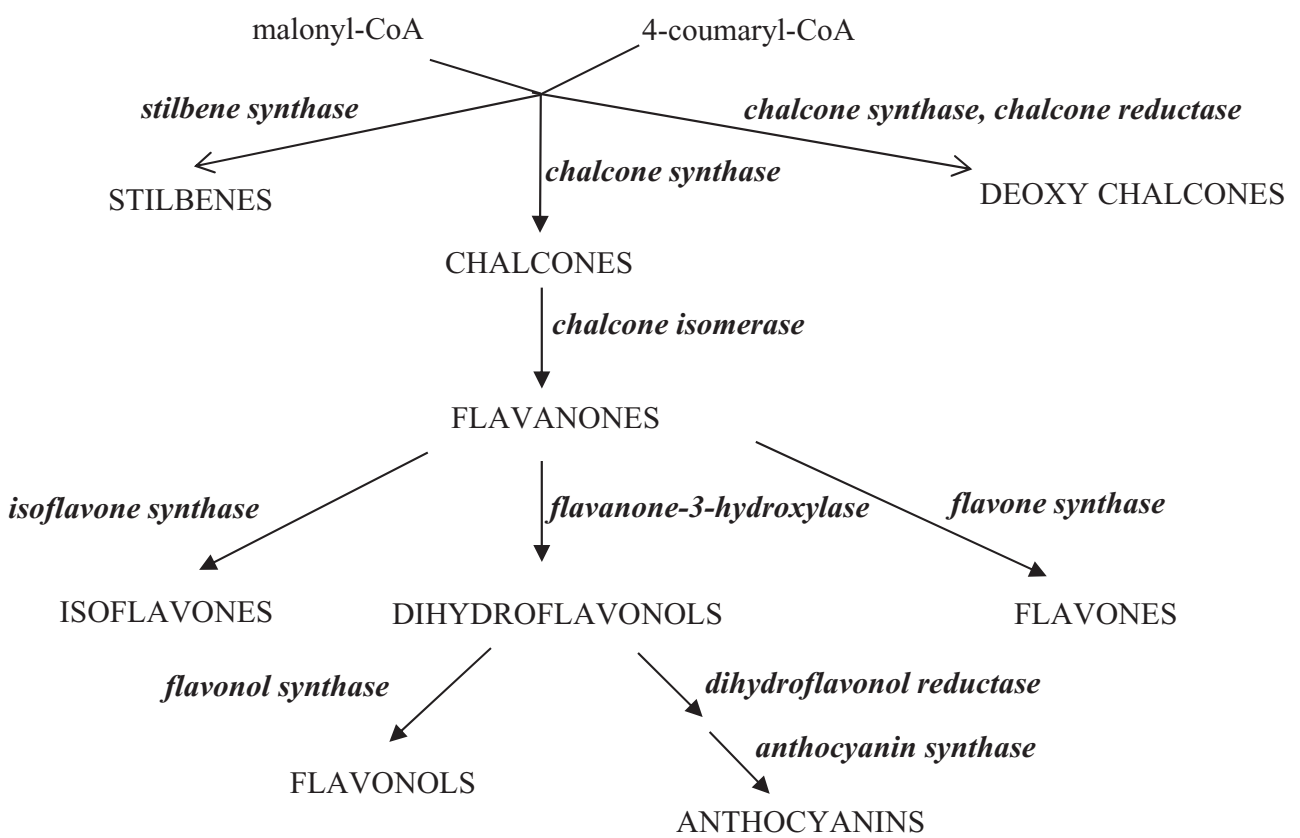

FIG. 8. Flavonoid biosynthetic pathway. Types of flavonoids are in capital letters. 
overexpressed in tomato and resulted in a greater than 70-fold increase in quercetin, a type of flavonol (Muir et al., 2001). In a similar study, two maize transcription factors were expressed in tomato to improve flavonol content (Bovy et al., 2002). These genes, leaf color $(L C)$ and colorless $1(C 1)$, induce flavonoid gene expression in maize and were expressed exclusively in tomato fruit. Fruit flesh of the transgenic plants had increased levels of the flavonol kaempferol (60-fold increase) and the flavanone naringenin. Three flavonoid biosynthetic branches were introduced to tomato by genetic engineering to produce stilbenes, deoxychalcones and flavones that are naturally not produced in tomato fruit (Schijlen et al., 2006). In order to direct the flux in the flavonoid pathway towards stilbene production, tomato cultivar Moneymaker was transformed with the grape stilbene synthase gene under the control of a double CaMV $35 \mathrm{~S}$ promoter. Plants constitutively expressing the transgene had high levels of stilbenes, predominantly resveratrol and piceid, in the fruit peel. In addition to the high levels measured in fruit peel, stilbene production was also detected in the fruit flesh. For the production of deoxychalcones, a chalcone synthase gene from petunia and a chalcone reductase gene from alfalfa were inserted to tomato in a single construct, each under the control of the double CaMV 35S promoter. Deoxychalcone accumulation was significant in the fruit peel, with butein and isoliquiritigenin being the main deoxychalcones detected. The third construct that was tested had petunia chalcone isomerase and gerbera flavone synthase genes, each controlled by double CaMV 35S promoters. The resulting transgenic tomatoes had high levels of flavones, accumulated mainly as luteolin-7-glucoside and luteolin aglycone, and flavonols, mainly quercetin glycosides and kaempferol glycosides, in the fruit peel. More than three-fold increase in the total antioxidant capacity of the tomato fruit peel was detected for the plants expressing the chalcone isomerase and flavone synthase transgenes. The expression patterns of the native flavonoid biosynthetic genes in flesh and peel should determine the accumulation of novel flavonoids mostly in the peel of the transgenic fruits.

Tomato fruits that accumulate anthocyanins both in their flesh and peel at comparable levels with blackberries and blueberries were produced by Butelli et al. (2008). Intense purple coloration of flesh and peel was achieved through the expression of two transcription factors from snapdragon (Antirrhinum majus) that regulate anthocyanin pigmentation. The snapdragon Delila and Roseal genes, each driven by the ripening-specific E8 promoter, accumulated high levels of anthocyanins in transgenic tomatoes and improved the hydrophilic antioxidant capacity of the fruits by three-fold. Genetically engineered canola (Brassica napus) plants with high levels of anthocyanins were also produced (Li et al., 2010). Constitutive expression of the Arabidopsis gene, production of anthocyanin pigment 1 (PAPl), resulted in purple-green color and increased antioxidant capacity in leaves due to the enhanced accumulation of anthocyanins, flavonoids and phenylpropanoids. However, when it is considered that canola is an oilseed crop species, the effect of transgene expression on the antioxidant properties in seeds should also be determined.

Improvement of potato antioxidant capacity through improving tuber anthocyanin pigmentation has also been a focus of research. Tissue-specific accumulation of red and purple pigments in the tuber skin requires a dominant allele of locus $D$ (developer), a gene that has been known since 1910 (Salaman, 1910). D maps to a region of chromosome 10 (Van Eck et al., 1994), that harbors MYB transcription factor homologs that regulate anthocyanin biosynthesis. The pigmentation of tuber flesh $(P f)$ locus is tightly linked to locus $D$ (De Jong, 1987), and QTLs identified on chromosomes 5, 8, and 9 (Zhang et al., 2009) also regulate tuber flesh pigmentation. A candidate gene for locus $D$ was identified and constitutively expressed in white-skinned and light red-colored cultivars and two white-skinned diploid clones that lack the dominant allele of the $D$ locus. Transgenic tubers had uniform skin pigmentation, accompanied by pigmentation of tuber flesh, petals, and foliage (Jung et al., 2009). However, flesh anthocyanin pigmentation was neither complete nor uniform, implying that a functional allele of $D$ is insufficient for complete coloration of tuber flesh and that specific alleles of QTLs that influence flesh coloration are also required. Anthocyanidin 3-o-glucosyltransferase is a key enzyme in anthocyanin biosynthesis with a critical role in anthocyanin stability and water solubility (Wei et al., 2012). In a recent study that aimed to enhance anthocyanin synthesis in potato tubers, this enzyme was overexpressed in the light red skinned cultivar Desiree (Wei et al., 2012). Skin of the transgenic tubers had an up to three-fold improved anthocyanin content, which was visible to the eye as a deeper color with respect to wild type controls.

\section{MINERAL CONTENT MODIFICATION}

Humans require various minerals to maintain health and for proper growth (Welch, 2002). For example, iron and zinc deficiencies result in decreased immune function and can interfere with growth and development (Zimmermann and Hurrell, 2002). It is estimated that iron deficiency affects one third of the world's population and causes 800,000 deaths worldwide each year (Masuda et al., 2012). Plants are an important source of such essential minerals (Welch, 2002). Because plants cannot synthesize these minerals, they must be acquired from the soil. As a result, engineering of plant mineral content is quite different from modification of compounds, like proteins and vitamins, that the plant itself synthesizes. Approaches that can be used include increasing mineral uptake, storage and bioavailability (Lonnerdal, 2003). Transport of the mineral within the plant presents an additional level of complication. Although most minerals are transported by the xylem, some minerals are transported by the phloem (Grusak, 2002b). The xylem moves minerals to those tissues/organs with the greatest water loss-mostly to leaves. In contrast, the phloem preferentially transports compounds from source (photosynthetic) organs to sinks such as seeds, fruits and roots. Thus, depending on the method of transport and the 
consumed part of the plant, mineral content improvement may also require modification of the plant's normal transport system.

Research to improve the mineral composition of crop plants has mostly focused on iron content. Several reports exist in this particular area, most of which describe research that was performed on iron biofortification of the staple crop rice (Nandi et al., 2002; Goto et al., 1999; Drakakaki et al., 2000; Lucca et al., 2002; Vasconcelos et al., 2003). In some cases, introduction of novel iron-binding proteins was used to increase iron content. In early work, Nandi et al. (2002) expressed human lactoferrin, a major iron-binding protein in human breast milk, in rice endosperm. Each lactoferrin molecule binds two iron atoms. Grain from transgenic plants contained twice as much iron as untransformed grain. Although the increase in iron content was not sufficient for individuals with high iron requirements on a rice-based diet, it was thought to be promising for infants and children who require less iron (Nandi et al., 2002). In attempts to increase iron content by further increasing the plant's iron-binding capacity, soybean and common bean ferritins were introduced into rice and wheat (Goto et al., 1999; Drakakaki et al., 2000; Lucca et al., 2002). Each molecule of ferritin can bind 4,500 iron atoms. Thus, ferritin is an excellent iron-storage protein. When the gene for soybean ferritin was introduced into rice, the resulting transgenic plants had twoto three-fold more iron than nontransformed individuals (Goto et al., 1999). Similar work with a Phaseolus vulgaris ferritin gene doubled the iron content of rice (Lucca et al., 2002). In the same work, Lucca et al. (2002) also attempted two methods to increase the bioavailability of iron in transgenic rice. Grains and legumes contain high levels of phytic acid, a compound that inhibits iron absorption by humans. In order to decrease this inhibition, the researchers introduced a thermo-tolerant phytase gene from Aspergillus into rice endosperm that was also expressing the ferritin gene from common bean. At the same time, a cysteine-containing peptide was introduced into the plants as it is known that such peptides can enhance mineral absorption. Although a 130 -fold increase in phytase and a seven-fold increase in cysteine residues were obtained, most of the phytase activity was lost after cooking.

Drakakaki et al. (2005) followed a similar strategy as Lucca et al. (2002) with the aim of increasing the iron content and bioavailability of maize seeds. Like Lucca et al. (2002) the researchers also used the soybean ferritin to improve the iron content. However, they did not use a thermostable phytase, as strongly reduced phytic acid levels in cereals cause severe yield losses. Aspergillus phytase was expressed in maize seeds both individually and along with ferritin from soybean. A reduction up to $95 \%$ of the phytate content in transgenic maize seeds was found to take place during food preparation that involves the steps of mixing the flour with water and incubation prior to cooking. Experiments using an in vitro system that simulated human digestion displayed increased availability of iron due to phytase activity. Transgenic maize seeds expressing both the Aspergillus phytase and soybean ferritin had in- creased iron content accompanied by three times improved iron bioavailability.

Expression of soybean ferritin in transgenic rice grains was shown to give rise to higher iron and zinc levels simultaneously (Vasconcelos et al., 2003). Non-polished grains accumulated $71 \mu \mathrm{g} / \mathrm{g}$ iron and $55.5 \mu \mathrm{g} / \mathrm{g}$ zinc while polished grains also had increased iron content reaching $37 \mu \mathrm{g} / \mathrm{g}$ in the best performing line. Simultaneous increase in zinc content was attributed to a possible common mechanism that regulates the transport of both minerals. Uptake of divalent cations other than iron was reported to be affected by enzymes that regulate iron uptake (Grusak et al., 1990; Welch et al., 1993; Delhaize, 1996; Cohen et al., 1998; Vasconcelos et al., 2003; Qu et al., 2005). In this case, it is crucial to take into account and investigate the accumulation of undesirable metals in plants that are engineered for increased iron uptake/storage.

The relationship between increased iron accumulation and expression of an exogenous ferritin was investigated in rice $(\mathrm{Qu}$ et al., 2005). Towards this aim, different degrees of ferritin overexpression were observed in the study. The rice Globulin promoter, whose activity was shown to be more than ten-fold higher than the rice Glutelin promoter, was used to overexpress the soybean ferritin gene. Double transgenic rice lines, expressing soybean ferritin under the control of the rice Glutelin $(G l u B-1)$ and Globulin $(G l b-1)$ promoters, were produced by transforming the ferritin overexpressing transgenic lines, GluB-1/SoyferH-1, of Goto et al. (1999) with the Glb-1/SoyferH-1 construct. Single transgenic plants expressing soybean ferritin under the control of the $G l b-1$ promoter $(G l b-1 / S o y f e r H-1)$ were also produced in the study. In order to investigate the effect of ferritin overexpression on iron uptake, double (GluB-1/SoyferH-1 and Glb-1/SoyferH1) and single (Glb-1/SoyferHI) transgenic lines produced in the study were compared with the GluB-1/SoyferH-1 lines of Goto et al. (1999). Single and double transgenic lines produced in the study had similar maximum iron concentrations in the endosperm as previously reported lines (Goto et al., 1999; Lucca et al., 2002; Vasconcelos et al., 2003) with no significant elevation in iron content due to stronger $G l b-1$ expression. Leaves of all examined ferritin-overexpressing lines had reduced iron content compared to wild type plants, indicating that iron uptake from the soil, rather than ferritin expression, is the major limiting factor for iron storage in rice endosperm. In the same study, accumulation of the major divalent cations was also investigated for the ferritin-overexpressing lines, and no harmful metal accumulation was observed. With the exceptions of magnesium and zinc concentrations, which were found to be higher in ferritinoverexpressing plants, concentrations of divalent cations did not display any significant difference from non-transformed plants.

Another approach to improve the mineral content in grains is increasing the expression of the nicotinamine synthase (NAS) gene (Lee et al., 2009). Nicotinamine synthase is a metal cation chelator and a key component of metal assimilation and homeostasis in higher plants. Rice has three NAS genes whose expression was found to be differentially regulated by iron. Activation 
tagging of the rice OsNAS3 gene by using $35 \mathrm{~S}$ enhancer elements improved grain iron content by 2.9 -fold. Increased iron content was accompanied by elevated levels of zinc and copper in transgenic grain. Bioavailability tests with anemic mice showed improved iron bioavailability of OsNAS3 overexpressing grains with respect to wild type (Lee et al., 2009). Similarly, enhanced expression of $O S N A S 2$ improved iron content and bioavailability of transgenic rice seeds (Lee et al., 2012). The NAS gene from Arabidopsis was used together with ferritin from common bean and phytase from Aspergillus fumigatus to improve the iron content of rice (Wirth et al., 2009). NAS was expressed constitutively under the control of the CaMV $35 \mathrm{~S}$ promoter while the ferritin and phytase genes were each expressed under the control of the rice seed storage Globulin promoter. Resultant grain expressing the multiple transgenes displayed more than six-fold improved iron content. In another study that followed a multigenic approach, soybean ferritin (soyferH2), barley nicotinamine synthase (HvNASI) and rice nicotinamine-metal transporter (OSYSL2) genes were expressed in rice (Masuda et al., 2012). Combined expression of the three transgenes resulted in elevated levels of seed iron content accompanied by improved zinc content. Field trials showed up to 4.4-fold improved iron content of polished $\mathrm{T}_{2}$ seeds.

While much more common in females, osteoporosis is a condition that affects both genders (Orwoll and Klein, 1995). Inadequate dietary calcium intake increases the frequency and severity of the condition which results in reduced bone mass (Connolly, 2008). In contrast with dairy products, plants are relatively poor sources of calcium (White and Broadley, 2009). Thus, efforts to improve the accumulation of this mineral in edible tissues of crop plants are important in terms of alleviating the incidence of osteoporosis. Carrot was the target of pioneering work to increase calcium content in an edible plant species (Park et al. 2004). Park et al. (2004) overexpressed a truncated form of the Arabidopsis $\mathrm{H}^{+} / \mathrm{Ca}^{2+}$ transporter, cation exchanger $1(C A X I)$, which lacks its auto-inhibitory domain, in carrot. Increased calcium transport to vacuoles due to transgene activity resulted in 1.6-fold improved calcium content in transgenic roots relative to control without a reduction in yield or fertility. When bioavailability of the calcium content in transgenic carrots was assayed by feeding studies with mice and humans, transgenic carrot proved a better source of calcium for both organisms (Morris et al., 2008). The truncated form of Arabidopsis CAXI (sCAXI) and another $\mathrm{H}^{+} / \mathrm{Ca}^{2+}$ transporter CAX4 from Arabidopsis, were expressed in tomato (Park et al., 2005a). Although it successfully improved fruit calcium content, $s C A X 1$ expression led to calcium deficiency-like symptoms in transgenic plants which had severely altered development and morphology. Compared to $S C A X 1$ expressing tomatoes, $C A X 4$ overexpressing plants displayed a modest improvement in calcium content, but no alterations in plant morphology and development were apparent. In addition to the work with carrot, attempts to improve the calcium content of potato tubers also proved successful (Park et al., 2005b; Kim et al., 2006). Trans- genic tubers expressing Arabidopsis $s C A X 1$ displayed up to three-fold more calcium content compared to wild type without significant alterations in growth and development. The trait was also found to be stably inherited when monitored over three generations (Park et al., 2005b). In other work, a chimeric, Nterminus truncated Arabidopsis cation transporter $(C A X 2 B)$ that contains a domain from $C A X 1$ for increased substrate specificity, was overexpressed in potato to improve calcium accumulation (Kim et al., 2006). The transgenic plants had 50\% to 65\% improved tuber calcium content relative to wild type, with stable inheritance and no deleterious effects on plant growth or development. Arabidopsis $s C A X 1$ was also used for lettuce calcium biofortification (Park et al., 2009). Transgene overexpression did not cause any symptoms of altered growth or morphology and resulted in $25 \%$ to $32 \%$ improved calcium content in the edible parts of $\mathrm{T}_{2}$ plants compared to wild type. In addition, the level of the calcium antinutrient, calcium oxalate, was reported as undetectable in transgenic plants. Sensory characteristics of transgenic lettuce were also evaluated and no significant difference was detected between wild type and calcium biofortified plants.

\section{REDUCTION OF PLANT ALLERGENS}

Including the well-known examples of peanuts, tree nuts and soybean, proteins of several plant species elicit serious food allergies (Zuidmeer et al., 2008). Post-transcriptional silencing of genes that encode plant allergens is a promising strategy to completely prevent or at least minimize the production of such proteins in the edible parts of plant species (Singh and Bhalla, 2008). However, the resultant plant can be considered hypoallergenic only if all of the proteins that contribute to allergenicity are simultaneously removed. Relevant literature has reported plant allergens that are products of housekeeping genes, which should be replaced by non-allergenic counterparts in case of complete downregulation (Le et al., 2006a).

Early work with rice successfully reduced the amount of $14 \mathrm{kDa}$ and $16 \mathrm{kDa}$ seed allergen proteins through seed-specific expression of an antisense construct designed for $16 \mathrm{kDa}$ proteins (Tada et al., 1996). A major allergen identified in soybean is a minor seed constituent, Gly m Bd 30K (Herman et al., 2003). This protein is reported to be the cause of more than $65 \%$ of soybean sensitivity incidents. Complete suppression of Gly $\mathrm{m} \mathrm{Bd}$ $30 \mathrm{~K}$ related peptides was achieved by constitutive expression of a Gly $\mathrm{m} \mathrm{Bd} 30 \mathrm{~K}$ open reading frame. Transgenic plants and seeds that lacked Gly $\mathrm{m}$ Bd $30 \mathrm{~K}$ proteins displayed similar phenotypic and compositional characteristics with wild type. Most individuals with birch pollen allergy are also allergic to apples due to the cross-reactivity of immunoglobulin $\mathrm{E}$ with the Mal $\mathrm{d} 1$ protein that is expressed in apple leaves and fruits (Gilissen et al., 2005). Although symptoms of apple allergy are mild, allergic individuals generally tend to avoid consuming this nutritious fruit. Gilissen et al. (2005) transformed in vitro grown apple plantlets with a Mal d 1 specific intron-spliced hairpin construct in order 
to establish post-transcriptional silencing of Mal d 1 expression. Reduced Mal d 1 expression was confirmed by immunoblotting and leaves of wild type plantlets displayed significantly higher allergenicity compared to leaves from the transformants in skin prick tests. However, since Mal d 1 family proteins function in plant defense, mature transgenic plants must be investigated for altered response to biotic and abiotic stresses. Tomato allergens, Lyc 1 and Lyc 3 were also targeted for reduced accumulation through RNAi silencing (Le et al., 2006a; Le et al., 2006b). Profilins are small, actin-binding proteins that are found in every eukaryotic cell. Similar to many plant profilins, tomato profilins, Lyc e 1.01 and Lyc e 1.02, are identified as allergens and RNAi silencing strategy was employed to downregulate their expression (Le et al., 2006a). The approach proved successful to reduce Lyc e 1 expression 10-fold in transgenic fruits, however, since these profilins carry out housekeeping functions, downregulating their expression resulted in severe growth retardation and yield reduction. In contrast, when the expression of Lyc e 3 (a non-specific lipid transfer protein) was suppressed, no adverse effect on plant phenotype was observed although the level of Lyc 3 accumulation was below the limit of detection in transgenic fruits (Le et al., 2006b). Peanut allergy is one of the most dangerous food allergies and anaphylaxis induced by peanuts in susceptible individuals can be lethal (Zuidmeer et al., 2008). In most cases, a single kernel is sufficient to trigger the allergic reaction. Accidental consumption of peanuts is a common case, as peanuts are extensively used in many products by the food industry (Singh and Bhalla, 2008). Using an RNAi strategy, Dodo et al. (2008) successfully reduced the content of the immunodominant peanut allergen, Ara h 2, in seeds from $\mathrm{T}_{0}$ plants. Allergenicity of transgenic seeds was evaluated and found to be reduced compared to wild type. In similar work, Chu et al. (2008) suppressed the production of two immunodominant allergens, Ara h 2 and Ara h 6 simultaneously, leading to significant reduction in allergenicity.

\section{CONCLUSIONS}

Although considerable progress toward biotechnological improvement of nutritional quality has been made in the last few years, more research in several key areas is needed. In order to effectively engineer a given metabolic trait, knowledge of the biosynthetic and/or transport pathway(s) involved is essential. Functional genomics and other gene discovery methods are valuable for elucidating such pathways. It is also necessary to understand the relationships among different biosynthetic pathways because modification of one pathway may have repercussions on linked pathways. Because much of the research on biosynthetic pathways is conducted on model plants, like Arabidopsis, it is essential that this knowledge be transferred to agronomically important crops.

Improved accumulation of a phytonutrient in a target plant tissue does not necessarily lead to improved uptake and health when consumed by humans. Research investigating bioavail- ability of the compound and the effective dose for a biological effect are essential to evaluate nutritional quality. Bioavailability may be influenced by several factors such as chemical form of the nutrient, solubility in food matrix, copresentation with nutritional enhancers or antinutritional compounds and food processing conditions. A striking example is provided by research on bioavailability of lycopene in tomato (Unlu et al., 2007). While the cis-isomer was found to be preferentially absorbed by humans, all-trans-lycopene was found as the predominant isoform in processed and fresh tomatoes. High temperature processing of the tomato matrix in the presence of oil enhances cis-isomerization and leads to improved bioavailability, highlighting the necessity to consider all possible contributors to bioavailability. Studies investigating vitamin A bioavailability of Golden Rice showed that $\beta$-carotene is efficiently converted to vitamin A when consumed by humans (Tang et al., 2009). Recently, $\beta$-carotene in Golden Rice was shown to be as effective as $\beta$-carotene in oil to provide vitamin A for children (Tang et al., 2012). However, such reports on the bioavailability of phytonutrients are limited.

Bioavailability is not the only factor which must be considered, agronomic and quality traits also must be investigated in the engineered plants. The targets of nutritional improvement often have multiple roles in plant metabolism and physiology. Thus, alteration in their levels can have negative effects on plant yield and alter susceptibility or resistance to various biotic and abiotic stresses. Such undesired changes may result in a crop which is rejected by growers because of its poor field performance. Engineered plants may also have more subtle changes in metabolites which alter plant growth, product quality and non-targeted nutritional traits. Thus, the development of an engineered plant containing increased levels of a certain nutrient is only the first step toward a commercially-viable crop. The altered plant must be thoroughly vetted in the field or greenhouse (depending on the normal production conditions) to ensure that yield, quality and nutrition factors are comparable to the best cultivars and suitable for agricultural production. Fortunately, high-speed genomic and metabolomic techniques are now available to expedite some of these analyses.

Although biotechnology has proven successful in improving the nutritional value of a wide variety of crop species, only a few of such crops are approved for human consumption. These crops include soybean lines with altered oil properties (high oleic acid, high omega-3 fatty acid and decreased saturated fatty acids), maize with increased lysine content and rice with reduced allergenicity (ISAAA, 2012). Since the aim of such work is to alleviate nutrient-related health problems, regulatory approval and commercialization defines the usefulness of the biofortification strategy. The case of Golden Rice exemplifies this as it has not yet been approved for commercialization. Thus, in addition to scientific questions, societal questions involved in the biotechnological improvement of nutritional quality must be considered. Although it is not the purpose of this review to detail these considerations, they must be addressed before beginning 
such research as the work itself and the regulatory approval process are very expensive and time-consuming. Therefore, target traits for improvement must be carefully selected and a clear need for the use of biotechnology (rather than classical breeding methods) must be demonstrated before work is started. The expected benefits of a given product must also be weighed against any possible safety concerns. Grower and consumer acceptance must also be obtained. Finally, because many of the traits of interest are most beneficial for those in undeveloped or developing countries, delivery of nutritionally improved crops to those who need them most must be considered.

\section{ACKNOWLEDGMENT}

The authors are grateful to Elizabeth D. Earle for critical comments on the manuscript.

\section{REFERENCES}

Abbadi, A., Domergue, F., Bauer, J., Napier, J. A., Welti, R., Zahringer, U., Cirpus, P., and Heinz, E. 2004. Biosynthesis of very long chain polyunsaturated fatty acids in transgenic oilseeds: constraints on their accumulation. Plant Cell 16: 2734-2748.

Abhary, M., Siritunga, D., Stevens, G., Taylor, N. J., and Fauquet, C. M. 2011. Transgenic biofortification of the starchy staple cassava (Manihot esculenta) generates a novel sink for protein. PLOS ONE 6: e16256.

Agius, F., Gonzalez-Lamothe, R., Caballero, J. L., Munoz-Blanco, J., Botella, M. A., and Valpuesta, V. 2003. Engineering increased vitamin C levels in plants by overexpression of a D-galacturonic acid reductase. Nat. Biotechnol. 21: $177-181$.

Ahn, M. J., Noh, S. A., Ha, S. H., Back, K., Lee, S. W., and Myung Bae, J. M. 2012. Production of ketocarotenoids in transgenic carrot plants with an enhanced level of $\beta$-carotene. Plant Biotechnol. Rep. 6: 133-140.

Akhtar, T. A., Orsomando, G., Mehrshahi, P., Lara-Nunez, A., Bennett, M. J., Gregory III, J. F., and Hanson, A. D. 2010. A central role for gamma-glutamyl hydrolases in plant folate homeostasis. Plant J. 64: 256-266.

Aluru, M., Xu, Y., Guo, R., Wang, Z., Li, S., White, W., Wang, K., and Rodermel, S. 2008. Generation of transgenic maize with enhanced provitamin A content. J. Exp. Bot. 59: 3551-3562.

Apel, W., and Bock, R. 2009. Enhancement of carotenoid biosynthesis in transplastomic tomatoes by induced lycopene-to-provitamin A conversion. Plant Physiol. 151: 59-66.

Avraham, T., Badani, H., Galili, S., and Amir, R. 2005. Enhanced levels of methionine and cysteine in transgenic alfalfa (Medicago sativa $\mathrm{L}$.) plants overexpressing the Arabidopsis cystathionine $\gamma$-synthase gene. Plant Biotechnol. J. 3: 71-79.

Basset, G. J. C., Quinlivan, E. P., Gregory, J. F., and Hanson, A. D. 2005. Folate synthesis and metabolism in plants and prospects for biofortification. Crop Sci. 45: 449-453.

Bazzano, L. A., He, J., Ogden, L. G., Loria, C. M., Vupputuri, S., Myers, L., and Whelton, P. K. 2002. Fruit and vegetable intake and risk of cardiovascular disease in US adults: the first national health and nutrition examination survey epidemiologic follow-up study. Am. J. Clin. Nutr. 76: 93-99.

Bekaert, S., Storozhenko, S., Mehrshahi, P., Bennett, M. J., Lambert, W., Gregory, J. F., Schubert, K., Hugenholtz, J., Van Der Straeten, D., and Hanson, A. D. 2008. Folate biofortification in food plants. Trends Plant Sci. 13: 28-35.

Bhullar, N. K., and Gruissem, W. 2013. Nutritional enhancement of rice for human health: the contribution of biotechnology. Biotech. Adv. 31: 50-57.

Blokhina, O., Virolainen, E., and Fagerstedt, K. V. 2003. Antioxidants, oxidative damage and oxygen deprivation stress: a review. Ann. Bot. 91: 179-194.
Bovy, A., de Vos, R., Kemper, M., Schijlen, E., Pertejo, M. A., Muir, S., Collins, G., Robinson, S., Verhoeyen, M., Hughes, S., Santo-Buelga, C., and van Tunen, A. 2002. High-flavonol tomatoes resulting from the heterologous expression of the maize transcription factor genes $L C$ and Cl. Plant Cell 14: 2509-2526.

Bramley, P. M., Elmadfa, I., Kafatos, A., Kelly, F. J., Manios, Y., Roxborough, H. E., Schuch, W., Sheehy, P. J. A., and Wagner, K. H. 2000. Vitamin E. J. Sci. Food Agr. 80: 913-938.

Breithaupt, D. E., and Bamedi, A. 2002. Carotenoids and carotenoid esters in potatoes (Solanum tuberosum) new insights into an ancient vegetable. $J$. Agric. Food Chem. 50: 7175-7181.

Butelli, E., Titta, L., Giorgio, M., Mock, H. P., Matros, A., Peterek, S., Schijlen, E. G. W. M., Hall, R. D., Bovy, A. G., Jie Luo, J., and Martin, C. 2008. Enrichment of tomato fruit with health-promoting anthocyanins by expression of select transcription factors. Nat. Biotechnol. 26: 13011308.

Chen, Z., Young, T. E., Ling, J., Chang, S. C., and Gallie, D. R. 2003. Increasing vitamin $\mathrm{C}$ content of plants through enhanced ascorbate recycling. PNAS 100: 3525-3530.

Cheng, B., Wu, G., Vrinten, P., Falk, K., Bauer, J., and Qiu, X. 2010. Towards the production of high levels of eicosapentaenoic acid in transgenic plants: the effects of different host species, genes and promoters. Transgenic Res. 19: $221-229$.

Christianson, D. D., Khoo, U., Nielsen, H. C., and Wall, J. S. 1974. Influence of Opaque-2 and Floury-2 genes on formation of proteins in particulates of corn endosperm. Plant Physiol. 53: 851-857.

Chu, Y., Faustinelli, P., Ramos, M. L., Hajduch, M., Stevenson, S., Thelen, J. J., Maleki, S. J., Cheng, H., and Ozias Akins, P. 2008. Reduction of IgE binding and nonpromotion of Aspergillus flavus fungal growth by simultaneously silencing Ara h 2 and Ara h 6 in peanut. J. Agric. Food Chem. 56: 11225-11233.

Cohen, K. C., Fox, T. C., Garvin, D. F., and Kochian, L. V. 1998. The role of iron-deficiency stress in stimulating heavy-metal transport in plants. Plant Physiol. 116: 1063-1672.

Coleman, C. E., and Larkins, B. A. 1999. The prolamins of maize. In: Seed Proteins. pp. 109-139. Shewry, P. R., and Casey, R., Eds., Kluwer Academic Pubs, Dordrecht, The Netherlands.

Cong, L., Wang, C., Chen, L., Liu, H., Yang, G., and He, G. 2009. Expression of phytoene synthase 1 and carotene desaturase crtI genes result in an increase in the total carotenoids content in transgenic elite wheat (Triticum aestivum L.). J. Agric. Food Chem. 57: 8652-8660.

Connolly, E. L. 2008. Raising the bar for biofortification: enhanced levels of bioavailable calcium in carrots. Trends Biotechnol. 26: 401-403.

Cunningham, F. X. Jr, and Gantt, E. 2005. A study in scarlet: enzymes of ketocarotenoid biosynthesis in the flowers of Adonis aestivalis. Plant J. 41: 478-492.

D’Ambrosio, C., Giorio, G., Marino, I., Merendino, A., Petrozza, A., Salfi, L., Stigliani, A. L., and Cellini, F. 2004. Virtually complete conversion of lycopene into $\beta$-carotene in fruits of tomato plants transformed with the tomato lycopene $\beta$-cyclase (tlcy-b) cDNA. Plant Sci. 166: 207-214.

Dancs, G., Kondrak, M., and Banfalvi, Z. 2008. The effects of enhanced methionine synthesis on amino acid and anthocyanin content of potato tubers. BMC Plant Biol. 8: 65.

Daniell, H., and Dhingra, A. 2002. Multigene engineering: dawn of an exciting new era in biotechnology. Curr. Opin. Biotechnol. 13: 136-141.

Davey, M. W., Van Montagu, M., Inze, D., Sanmartin, M., Kanellis, A., Smirnoff, N., Benzie, I. J. J., Strain, J. J., Flavell, D., and Fletcher, J. 2000. Plant Lascorbic acid: chemistry, function, metabolism, bioavailability and effects of processing. J. Sci. Food Agr. 80: 825-860.

De la Garza, R. D., Quinlivan, E. P., Klaus, S. M. J., Basset, G. J. C., Gregory III, J. F., and Hanson, A. D. 2004. Folate biofortification in tomatoes by engineering the pteridine branch of folate synthesis. PNAS 101: 13720-13725.

De la Garza, R. D., Gregory, J. F., and Hanson, A. D. 2007. Folate biofortification of tomato fruit. PNAS 104: 4218-4222. 
Delhaize, E. 1996. A metal-accumulator mutant of Arabidopsis thaliana. Plant Physiol. 111: 549-855.

De Jong, H. 1987. Inheritance of pigmented tuber flesh in cultivated diploid potatoes. Am. Potato J. 64: 337-343.

De Pascual-Teresa, S., and Sanchez-Ballesta, M. T. 2008. Anthocyanins: from plant to health. Phytochem. Rev. 7: 281-299.

Deshpande, S. S., Deshpande, U. S., and Salunkhe, D. K. 1996. Nutritional and health aspects of food antioxidants. In: Food Antioxidants: Technological, Toxicological and Health Perspectives. pp. 361-469. Madhavi, D. L., Deshpande, S. S., and Salunkhe, D. K., Eds., Marcel Dekker, Inc., New York, USA.

Dharmapuri, S., Rosati, C., Pallara, P., Aquilani, R., Bouvier, F., Camara, B., and Giuliano, G. 2002. Metabolic engineering of xanthophyll content in tomato fruits. FEBS Lett. 519: 30-34.

Diretto, G., Tavazza, R., Welsch, R., Pizzichini, D., Mourgues, F., Papacchioli, V., Beyer, P., and Giuliano, G. 2006. Metabolic engineering of potato tuber carotenoids through tuber-specific silencing of lycopene epsilon cyclase. BMC Plant Biol. 6:13.

Diretto, G., Welsch, R., Tavazza, R., Mourgues, F., Pizzichini, D., Beyer, P., and Giuliano, G. 2007a. Silencing of beta-carotene hydroxylase increases total carotenoid and beta-carotene levels in potato tubers. BMC Plant Biol. 7: 11.

Diretto, G., Al-Babili, S., Tavazza, R., Papacchioli, V., and Beyer, P. et al. 2007b. Metabolic engineering of potato carotenoid content through tuberspecific overexpression of a bacterial mini-pathway. PLOS ONE 2: e350.

Dodo, H. W., Konan, K. N., Chen, F. C., Egnin, M., and Viquez, O. M. 2008. Alleviating peanut allergy using genetic engineering: the silencing of the immunodominant allergen Ara $\mathrm{h} 2$ leads to its significant reduction and a decrease in peanut allergenicity. Plant Biotechnol. J. 6: 135-145.

Drakakaki, G., Christou, P., and Stoger, E. 2000. Constitutive expression of soybean ferritin cDNA in transgenic wheat and rice results in increased iron levels in vegetative tissues but not in seeds. Transgenic Res. 9: 445-452.

Drakakaki, G., Marcel, S., Glahn, R. P., Lund, E. K., Pariagh, S., Fischer, R., Christou, P., and Stoger, E. 2005. Endosperm-specific co-expression of recombinant soybean ferritin and Aspergillus phytase in maize results in significant increases in the levels of bioavailable iron. Plant Mol. Biol. 59: 869-880.

Ducreux, L. J. M., Morris, W. L., Hedley, P. E., Shepherd, T., Davies, H. V., Millam, S., and Taylor, M. A. 2005. Metabolic engineering of high carotenoid potato tubers containing enhanced levels of b-carotene and lutein. J. Exp. Bot. 56: $81-89$.

FAO, WFP, and IFAD. 2012. The state of food insecurity in the world 2012. Economic growth is necessary but not sufficient to accelerate reduction of hunger and malnutrition. Rome, FAO.

Farre, G., Sudhakar, D., Naqvi, S., Sandmann, G., Christou, P., Capell, T., and Zhu, C. 2012. Transgenic rice grains expressing a heterologous qhydroxyphenylpyruvate dioxygenase shift tocopherol synthesis from the $\gamma$ to the $\alpha$ isoform without increasing absolute tocopherol levels. Transgenic Res. 21: 1093-1097.

Fraser, P. D., Romer, S., Shipton, C. A., Mills, P. B., Kiano, J. W., Misawa, N., Drake, R. G., Schuch, W., and Bramley, P. M. 2002. Evaluation of transgenic tomato plants expressing an additional phytoene synthase in a fruit-specific manner. PNAS 99: 1092-1097.

Frizzi, A., Huang, S., Gilbertson, L. A., Armstrong, T. A., Luethy, M. H., and Malvar, T. M. 2008. Modifying lysine biosynthesis and catabolism in corn with a single bifunctional expression/silencing transgene cassette. Plant Biotechnol. J. 6: 13-21.

Fujisawa, M., Takita, E., Harada, H., Sakurai, N., Suzuki, H., Ohyama, K., Shibata, D., and Misawa, N. 2009. Pathway engineering of Brassica napus seeds using multiple key enzyme genes involved in ketocarotenoid formation. J. Exp. Bot. 60: 1319-1332.

Galili, G., and Amir, R. 2012. Fortifying plants with the essential amino acids lysine and methionine to improve nutritional quality. Plant Biotechnol. J. doi: 10.1111/pbi.12025.

Gilissen, L. J. W. J., Bolhaar, S. T. H. P., Matos, C. I., Rouwendal, G. J. A., Boone, M. J., Krens, F. A., Zuidmeer, L., van Leeuwen, A., Akkerdaas, J.,
Hoffmann Sommergruber, K., Knulst, A. C., Bosch, D., van de Weg, W. E., and van Ree, R. 2005. Silencing the major apple allergen Mal d 1 by using the RNA interference approach. J. Allergy Clin. Immunol. 115: 364-369.

Gillies, S. A., McIntosh, S. R., and Henry, R. J. 2008. A transgenic cereal crop with enhanced folate: rice expressing wheat HPPK/DHPS. 11th International Wheat Genetics Symposium, Brisbane, Qld, 24-28 August.

Goto, F., Yoshihara, T., Shigemoto, N., Toki, S., and Takaiwa, F. 1999. Iron fortification of rice seed by the soybean ferritin gene. Nat. Biotechnol. 17: 282-286.

Grusak, M. A., Welch, R. M., and Kochian, L. V. 1990. Physiological characterization of a single-gene mutant of Pisum sativum L. exhibiting excess iron accumulation. I. Root iron reduction and iron uptake. Plant Physiol. 93: 976-981.

Grusak, M. A. 2002a. Phytochemicals in plants: genomics-assisted plant improvement for nutritional and health benefits. Curr. Op. Biotech. 13: 508-511. Grusak, M. A. 2002b. Enhancing mineral content in plant food products. J. Am. Coll. Nutr. 21: 178S-183S.

Hacham, Y., Avraham, T., and Amir, R. 2002. The N-terminal region of Arabidopsis cystathionine gamma synthase plays an important role in methionine metabolism. Plant Physiol. 128: 454-462.

Hacham, Y., Schuster, G., and Amir, R. 2006. An in vivo internal deletion in the $\mathrm{N}$-terminus of cystathionine c-synthase in Arabidopsis results with decreased modulation of expression by methionine. Plant J. 45: 955-967.

Hacham, Y., Matityahu, I., Schuster, G., and Amir, R. 2008. Overexpression of mutated forms of aspartate kinase and cystathionine $\gamma$-synthase in tobacco leaves resulted in the high accumulation of methionine and threonine. Plant J. 54: 260-271.

Hanafy, M. S., Rahman, S. M., Nakamoto, Y., Fujiwara, T., Naito, S., Wasaka, K., and Ishimoto, M. 2013. Differential response of methionine metabolism in two grain legumes, soybean and azuki bean, expressing a mutated form of Arabidopsis cystathionine $\gamma$-synthase. J. Plant Physiol. 170: 338-345.

Harjes, C. E., Rocheford, T. R., Bai, L., Brutnell, T. P., Kandianis, C. B., Sowinski, S. G., Stapleton, A. E., Vallabhaneni, R., Williams, M., Wurtzler, E. T., Yan, J., and Buckler, E. S. 2008. Natural genetic variation in lycopene epsilon cyclase tapped for maize biofortification. Science 319: 330-333.

Haroldsen, V. M., Chi-Ham, C. L., Kulkarni, S., Lorence, A., and Bennett, A. B. 2011. Constitutively expressed DHAR and MDHAR influence fruit, but not foliar ascorbate levels in tomato. Plant Physiol. Bioch. 49: $1244-1249$.

Hasunuma, T., Miyazawa, S. I., Yoshimura, S., Shinzaki, Y., Tomizawa, K. I., Shindo, K., Choi S. K., Misawa, N., and Miyake, C. 2008. Biosynthesis of astaxanthin in tobacco leaves by transplastomic engineering. Plant J. 55: 857-868.

Hemavathi, Upadhyaya, C. P., Young, K. E., Akula, N., Kim, H., Heung, J. J., Ohc, O. M., Aswath, C. R., Chun, S. C., Kim, D. H., and Park, S. W. 2009. Over-expression of strawberry D-galacturonic acid reductase in potato leads to accumulation of vitamin $\mathrm{C}$ with enhanced abiotic stress tolerance. Plant Sci. 177: 659-667.

Hemavathi, Upadhyaya, C. P., Akula, N., Young, K. E., Chun, S. C., Kim, D. H., and Park, S. W. 2010. Enhanced ascorbic acid accumulation in transgenic potato confers tolerance to various abiotic stresses. Biotechnol. Lett. 32: 321-330.

Herman, E. M., Helm, R. M., Jung R., and Kinney, A. J. 2003. Genetic modification removes and immunodominant allergen from soybean. Plant Physiol. 132: $36-43$.

Hirschi, K. D. 2009. Nutrient biofortification of food crops. Annu. Rev. Nutr. 29: 401-421.

Hossain, T., Rosenberg, I., Selhub, J., Kishore, G., Beachy, R., and Schubert, K. 2004. Enhancement of folates in plants through metabolic engineering. PNAS 101: 5158-5163.

Houmard, N. M., Mainville, J. L., Bonin, C. P., Huang, S., Luethy, M. H., and Malvar, T. M. 2007. High-lysine corn generated by endosperm-specific suppression of lysine catabolism using RNAi. Plant Biotechnol. J. 5: 605-614.

Huang, S., Adams, W. R., Zhou, Q., Malloy, K. P., Voyles, D. A., Anthony, J., Kriz, A. L., and Luethy, M. H. 2004. Improving nutritional quality of maize 
proteins by expressing sense and antisense zein genes. J. Agric. Food Chem. 52: $1958-1964$.

Humphries, J. M., and Khachik, F. 2003. Distribution of lutein, zeaxanthin and related geometrical isomers in fruit, vegetables, wheat and pasta products. $J$. Agric. Food Chem. 51: 1322-1327.

ISAAA. 2012. GM approval database. (http://www.isaaa.org/gmapproval database/default.asp. Accessed Jan. 2013).

Jain, A. K., and Nessler, C. L. 2000. Metabolic engineering of an alternative pathway for ascorbic acid biosynthesis in plants. Mol. Breed. 6: 73-78.

Jayaraj, J., Devlin, R., and Punja, Z. 2008. Metabolic engineering of novel ketocarotenoid production in carrot plants. Transgenic Res. 17: 489-501.

Jung, C. S., Griffiths, H. M., De Jong, D. M., Cheng, S., Bodis, M., Kim T. S., and De Jong, W. S. 2009. The potato developer $(D)$ locus encodes an R2R3 MYB transcription factor that regulates expression of multiple anthocyanin structural genes in tuber skin. Theor. Appl. Genet. 120: 45-57.

Kang, H. J., Hwang, I. K., Kim, K. S., and Choi, H. C. 2003. Comparative structure and physicochemical properties of IIpumbyeo, a high quality japonica rice, and its mutant, Suweon 464. J. Agric. Food Chem. 51: 6598-6603.

Karunanandaa, B., Qi, Q., Hao, M., Baszis, S. R., Jensen, P. K., Wong, Y. H. H., Jiang, J., Venkatramesh, M., Gruys, K. J., Moshiri, F., Post Beittenmiller, D., Weissa, J. D., and Valentin, H. E. 2005. Metabolically engineered oilseed crops with enhanced seed tocopherol. Metab. Eng. 7: 384-400.

Kinney, A. J., Cahoon, E. B., and Hitz, W. D. 2002. Manipulating desaturase activities in transgenic crop plants. Biochem. Soc. Trans. 30: 1099-1103.

Kinney, A. J., Cahoon, E. B., Damude, H. G., Hitz, W. D., Kolar, C. W., and Liu, Z. B. 2004. Production of very long chain polyunsaturated fatty acids in oilseed plants. Canadian Patent Database Application: CA 2512589.

Kim, C. K., Han, J. S., Lee, H. S., Oh, J. Y., Shigaki T., Park, S. H., and Hirschi, K. 2006. Expression of an Arabidopsis CAX2 variant in potato tubers increases calcium levels with no accumulation of manganese. Plant Cell Rep. 25: $1226-1232$.

Kris-Etherton, P. M., Harris, W. S., and Appel, L. J. 2002. Fish consumption, fish oil, omega-3 fatty acids, and cardiovascular disease. Circulation 106: 2747-2757.

Lachapelle, M., and Drouin, G. 2011. Inactivation dates of the human and guinea pig vitamin C genes. Genetica 139: 199-207.

Le, L. Q., Mahler, V., Lorenz, Y., Scheurer, S., Biemelt, S., Vieths, S., and Sonnewald, U. 2006a. Reduced allergenicity of tomato fruits harvested from Lyc e 1-silenced transgenic tomato plants. J. Allergy Clin. Immunol. 118: 1176-1183.

Le, L. Q., Lorenz, Y., Scheurer, S., Fötisch, K., Enrique, E., Bartra, J., Biemelt, S., Vieths, S., and Sonnewald, U. 2006b. Design of tomato fruits with reduced allergenicity by dsRNAi-mediated inhibition of ns-LTP (Lyc e 3) expression. Plant Biotechnol. J. 4: 231-242.

Lee, S., Jeon, U. S., Lee, S. J., Kim, Y. K., Persson, D. P., Husted, S., Schjorring, J. K., Kakei, Y., Masuda, H., Nishizawa, N. K., and An, G. 2009. Iron fortification of rice seeds through activation of the nicotianamine synthase gene. PNAS 106: 22014-22019.

Lee, S., Kim, Y. S., Jeon, U. S., Kim, Y. K., Schjoerring, J. K., and An, G. 2012. Activation of rice nicotianamine synthase 2 (OsNAS2) enhances iron availability for biofortification. Mol. Cells 33: 269-275.

Li, X., Gao, M. J., Pan, H. Y., Cui, D. J., and Gruber, M. Y. 2010. Purple canola: Arabidopsis PAP1 increases antioxidants and phenolics in Brassica napus leaves. J. Agric. Food Chem. 58: 1639-1645.

Lonnerdal, B. 2003. Genetically modified plants for improved trace element nutrition. J. Nutr. 133: 1490S-1493S.

Lopez, A. B., Van Eck, J., Conlin, B. J., Paolillo, D. J., O’Neill, J., and Li, L. 2008. Effect of the cauliflower Or transgene on carotenoid accumulation and chromoplast formation in transgenic potato tubers. J. Exp. Bot. 59: 213-223.

Lu, S., Van Eck, J., Zhou, X., Lopez, A. B., O'Halloran, D. M., Cosman, K. M., Conlin, B. J., Paolillo, D. J., Garvin, D. F., Vrebalov, J., Kochian, L. V., Kupper, H., Earle, E. D., Cao, J., and Li, L. 2006. The cauliflower Or gene encodes a DnaJ cysteine-rich domain-containing protein that mediates high levels of $\beta$-carotene accumulation. Plant Cell 18: 3594-3605.
Lucca, P., Hurrell, R., and Potrykus, I. 2002. Fighting iron deficiency anemia with iron-rich rice. J. Am. Coll. Nutr. 21: 184S-190S.

Maliga, P. 2004. Plastid transformation in higher plants. Ann. Rev. Plant Biol. 55: $289-313$.

Masuda, H., Ishimaru, Y., Aung, M. S., Kobayashi, T., Kakei, Y., Takahashi, M., Higuchi, K., Nakanishi, H., and Nishizawa, N. K. 2012. Iron biofortification in rice by the introduction of multiple genes involved in iron nutrition. Sci. Rep. 2: 543.

Mazur, B., Krebbers, E., and Tingey, S. 1999. Gene discovery and product development for grain quality traits. Science 285: 372-375.

Mehta, R. A., Cassol, T., Li, N., Ali, N., Handa, A. K., and Mattoo, A. K. 2002. Engineered polyamine accumulation in tomato enhances phytonutrient content, juice quality and vine life. Nat. Biotechnol. 20: 613-618.

Morell, M. K., and Myers, A. L. 2005. Towards the rational design of cereal starches. Curr. Opin. Plant Biol. 8: 1-7.

Morris, J., Hawthorne, K. M., Hotze, T., Abrams, S. A., and Hirschi, K. D. 2008. Nutritional impact of elevated calcium transport activity in carrots. PNAS 105: 1431-1435.

Muir, S. R., Collins, G. J., Robinson, S., Hughes, S. G., Bovy, A. G., de Vos, C. H., van Tunen, A. J., and Verhoeyen, M. E. 2001. Overexpression of petunia chalcone isomerase in tomato results in fruit containing dramatically increased levels of flavonols. Nat. Biotechnol. 19: 470-474.

Nandi, S., Suzuki, Y., Huang, J., Yalda, D., Pham, P., Wu, L., Bartley, G., Huang, N., and Lonnerdal, B. 2002. Expression of human lactroferrin in transgenic rice grains for the application of infant formula. Plant Sci. 163: 713-722.

Napier, J. A., and Graham, I. A. 2010. Tailoring plant lipid composition: designer oilseeds come of age. Curr. Opin. Plant Biol. 13: 330-337.

Naqvi, S., Zhu, C., Farre, G., Ramessar, K., Bassie, L., Breitenbach, J., Conesa, D. P., Ros, G., Sandmann, G., Capella, T., and Christou, P. 2009. Transgenic multivitamin corn through biofortification of endosperm with three vitamins representing three distinct metabolic pathways. PNAS 106: 7762-7767.

Naqvi, S., Farre, G., Zhu, C., Sandmann, G., Capell, T., and Christou, P. 2011. Simultaneous expression of Arabidopsis q-hydroxyphenylpyruvate dioxygenase and MPBQ methyltransferase in transgenic corn kernels triples the tocopherol content. Transgenic Res. 20: 177-181.

Orwoll, E. S., and Klein, R. F. 1995. Osteoporosis in men. Endocrine Rev. 16 87-116.

Paine, J. A., Shipton, C. A., Chaggar, S., Howells, R. M., Kennedy, M. J., Vernon, G., Wright, S. Y., and Hinchcliffe, E. 2005. Improving the nutritional value of Golden Rice through increased provitamin A content. Nat. Biotechnol. 23: 482-487.

Park, J. S., Chyun, J. H., Kim, Y. K., Line, L. L., and Chew, B. P. 2010. Astaxanthin decreased oxidative stress and inflammation and enhanced immune response in humans. Nutr. Metab. 7: 18.

Park, S., Kim, C. K., Pike, L. M., Smith, R. H., and Hirschi, K. D. 2004. Increased calcium in carrots by expression of an Arabidopsis $\mathrm{H}^{+} / \mathrm{Ca}^{2+}$ transporter. Mol. Breed. 14: 275-282.

Park, S., Cheng, N. H., Pittman, J. K., Yoo, K. S., Park, J., Smith, R. H., and Hirschi, K. D. 2005a. Increased calcium levels and prolonged shelf life in tomatoes expressing Arabidopsis $\mathrm{H}^{+} / \mathrm{Ca}^{2+}$ transporters. Plant Physiol. 139: 1194-1206.

Park, S., Kang, T. S., Kim, C. K., Han, J. S., Kim, S., Smith, R. H., Pike, L. M., and Hirschi, K. D. 2005b. Genetic manipulation for enhancing calcium content in potato tuber. J. Agric. Food Chem. 53: 5598-5603.

Park, S., Elless, M. P., Park, J., Jenkins A., Lim W., Chambers IV, E., and Hirschi, K. D. 2009. Sensory analysis of calcium-biofortified lettuce. Plant Biotechnol. J. 7: 106-117.

Qi, B., Fraser, T., Mugford, S., Dobson, G., Sayanova, O., Butler, J., Napier, J. A., Stobart, A. K., and Lazarus, C. M. 2004. Production of very long chain polyunsaturated omega-3 and omega-6 fatty acids in plants. Nat. Biotechnol. 22: 739-745.

Qin, A., Shi, Q., and Yu, X. 2011. Ascorbic acid contents in transgenic potato plants overexpressing two dehydroascorbate reductase genes. Mol. Biol. Rep. 38: $1557-1566$ 
Qu, L. Q., Yoshihara, T., Ooyama, A., Goto, F., and Takaiwa, F. 2005. Iron accumulation does not parallel the high expression level of ferritin in transgenic rice seeds. Planta 222: 225-233.

Raclaru, M., Gruber, J., Kumar, R., Sadre, R., Lühs, W., Zarhloul, M. K., Friedt, W., Frentzen, M., and Weier, D. 2006. Increase of the tocochromanol content in transgenic Brassica napus seeds by overexpression of key enzymes involved in prenylquinone biosynthesis. Mol. Breed. 18: 93-107.

Ralley, L., Enfissi, E. M. A., Misawa, N., Schuch, W., Bramley, P. M., and Fraser, P. D. 2004. Metabolic engineering of ketocarotenoid formation in higher plants. Plant J. 39: 477-486.

Ravanello, M. P., Ke, D., Alvarez, J., Huang, B., and Shewmaker, C. K. 2003. Coordinate expression of multiple bacterial carotenoid genes in canola leading to altered carotenoid production. Metab. Eng. 5: 255-263.

Rawsthorne, S. 2002. Carbon flux and fatty acid synthesis in plants. Prog. Lipid Res. 41: 182-196.

Regina, A., Bird, A., Topping, D., Bowden, S., Freeman, J., Barsby, T., Kosar Hashemi, B., Li, Z., Rahman, S., and Matthew, M. 2006. High-amylose wheat generated by RNA interference improves indices of large-bowel health in rats. PNAS 103: 3546-3551.

Reyes, A. R., Bonin, C. P., Houmard, N. M., Huang, S., and Malvar, T. M. 2009. Genetic manipulation of lysine catabolism in maize kernels. Plant Mol. Biol. 69: 81-89.

Rocheford, T. R., Wong, J. C., Egesel, C. O., and Lambert, R. J. 2002. Enhancement of vitamin E levels in corn. J. Am. Coll. Nutr. 21: 191S-198S.

Romer, S., Fraser, P. D., Kiano, J. W., Shipton, C. A., Misawa, N., Schuch, W., and Bramley, P. M. 2000. Elevation of the provitamin A content of transgenic tomato plants. Nat. Biotechnol. 18: 666-669.

Rosati, C., Aquilani, R., Dharmapuri, S., Pallara, P., Marusic, C., Tavazza, R., Bouvier, F., Camara, B., and Giuliano, G. 2000. Metabolic engineering of beta-carotene and lycopene content in tomato fruit. Plant J. 24: 413-419.

Salaman, R. N. 1910. The inheritance of colour and other characters in the potato. J. Genet. 1: 7-46.

Salamini, S. A., and Soavc, C. 1982. Zein: genetics and biochemistry. In: Maize for Biological Research. pp. 155-160. Sheridan, W. F., Eds., North Dakota Press, Grand Forks, ND, USA.

Sayre, R., Beeching, J. R., Cahoon, E. B., Egesi, C., Fauquet, C., Fellman, J., Fregene, M., Gruissem, W., Mallowa, S., Manary, M., Maziya Dixon, B., Mbanaso, A., Schachtman, D. P., Siritunga, D., Taylor, N., Vanderschuren, H., and Zhang, P. 2011. The BioCassava Plus Program: Biofortification of cassava for Sub-Saharan Africa. Annu. Rev. Plant Biol. 62: 251-272.

Schijlen, E., Ric de Vos, C. H., Jonker, H., van den Broeck, H., Molthoff, J., van Tunen, A., Martens, S., and Bovy, A. 2006. Pathway engineering for healthy phytochemicals leading to the production of novel flavonoids in tomato fruit. Plant Biotechnol. J. 4: 433-444.

Scott, M. P., Bhatnagar, S., and Betran, J. 2004. Tryptophan and methionine levels in quality protein maize breeding germplasm. Maydica 49: 303-311.

Sestili, F., Janni, M., Doherty, A., Botticella, E., D’Ovidio, R., Masci, S., Jones, H. D., and Lafiandra, D. 2010. Increasing the amylose content of durum wheat through silencing of the SBEIIa genes. BMC Plant Biol. 10: 144.

Sevenier, R., Hall, R. D., van der Meer, I. M., Hakkert, J. C., van Tunen, A. J., and Koops, A. J. 1998. High level fructan accumulation in a transgenic sugar beet. Nat. Biotechnol. 16: 843-846.

Sevenier, R., van der Meer I. M., Bino, R., Koops, A. J. 2002. Increased production of nutrients by genetically engineered crops. J. Am. Coll. Nutr. 21: 199S-204S.

Shewmaker, C. K., Sheehy, J. A., Daley, M., Colburn, S., and Ke, D. Y.1999. Seed-specific overexpression of phytoene synthase: increase in carotenoids and other metabolic effects. Plant J. 20: 401-412.

Singh, S. P., Zhou, X. R., Liu, Q., Stymne, S., and Green, A. G. 2005. Metabolic engineering of new fatty acids in plants. Curr. Opin. Plant. Biol. 8: 1-7.

Singh, M. B., and Bhalla, P. L. 2008. Genetic engineering for removing food allergens from plants. Trends Plant Sci. 13: 257-260.

Siritunga, D., and Sayre, R. 2004. Engineering cyanogen synthesis and turnover in cassava (Manihot esculenta). Plant Mol. Biol. 56: 661-669.
Storozhenko, S., De Brouwer, V., Volckaert, M., Navarrete, O., Blancquaert, D., Zhang, G. F., Lambert, W., and Van Der Straeten, D. 2007. Folate fortification of rice by metabolic engineering. Nat. Biotechnol. 25: 1277-1279.

Tada, Y., Nakase, M., Adachi, T., Nakamura, R., Shimada, H., Takahashi, M., Fujimura, T., and Matsuda, T. 1996. Reduction of 14-16 kDa allergenic proteins in transgenic rice plants by antisense gene. FEBS Lett. 391: 341-345.

Takeoka, G. R., Dao, L., Flessa, S., Gillepsie, D. M., Jewell, W. T., Huebner, B., Bertow, D., and Ebeler, S. E. 2001. Processing effects on lycopene content and antioxidant activity of tomatoes. J. Agric. Food. Chem. 49: 3713-3717.

Tang, G., Qin, J., Dolnikowski, G. G., Russell, R. M., and Grusak, M. A. 2009. Golden Rice is an effective source of vitamin A. Am. J. Clin. Nutr. 89: 1776-1783.

Tang, G., Hu, Y., Yin, S., Wang, Y., Dallal, G. E., Grusak, M. A., and Russel, R. M. 2012. $\beta$-Carotene in Golden Rice is as good as $\beta$-carotene in oil at providing vitamin A to children. Am. J. Clin. Nutr. 96: 658-664.

Tavva, V. S., Kim, Y. H., Kagan, I. A., Dinkins, R. D., Kim, K. H., and Collins, G. B. 2007. Increased $\alpha$-tocopherol content in soybean seed overexpressing the Perilla frutescens $\gamma$-tocopherol methyltransferase gene. Plant Cell. Rep. 26: 61-70.

Topping, D. L., and Clifton, P. M. 2001. Short-chain fatty acids and human colonic function: roles of resistant starch and nonstarch polysaccharides. Physiol. Rev. 81: 1031-1064.

Tucker, G. 2003. Nutritional enhancement of plants. Curr. Opin. Biotechnol. 14: $221-225$.

Ufaz, S., and Galili, G. 2008. Improving the content of essential amino acids in crop plants: goals and opportunities. Plant Physiol. 147: 954-961.

United Nations Children's Fund (UNICEF). 2009. Vitamin A deficiency: the challenge. (http://www.childinfo.org/vitamina.html. Accessed Jan. 2013).

United Nations Population Division. 2011. World Population Prospects: The 2010 Revision.

Unlu, N. Z., Bohn, T., Francis, D. M., Nagaraja, H. N., Clinton, S. K., and Schwartz, S. J. 2007. Lycopene from heat-induced cis-isomer-rich tomato sauce is more bioavailable than from all-trans-rich tomato sauce in human subjects. Brit. J. Nutr. 98: 140-146.

Van der Meer, I. M., Bovy, A. G., and Bosch, D. 2001. Plant-based raw material: improved food quality for better nutrition via plant genomics. Curr. Opin. Biotech. 12: 488-492.

Van Eck, H. J., Jacobs, J. M. E., Van Den Berg, P. M. M. M., Stiekema, W. J., and Jacobsen, E. 1994. The inheritance of anthocyanin pigmentation in potato (Solanum tuberosum L.) and mapping of tuber skin colour loci using RFLPs. Heredity 73: 410-421.

Van Eenennaam, A. L., Lincoln, K., Durrett, T. P., Valentin, H. E., Shewmaker, C. K., Thorne, G. M., Jiang, J., Baszis, S. R., Levering, C. K., Aasen, E. D., Hao, M., Stein, J. C., Norris, S. R., and Last, R. L. 2003. Engineering vitamin E content: from Arabidopsis mutant to soy oil. Plant Cell 15: 3007-3019.

Vasconcelos, M., Datta, K., Oliva, N., Khalekuzzaman, M., Torrizo, L., Krishnan, S., Oliveira, M., Goto, F., and Datta, S. K. 2003. Enhanced iron and zinc accumulation in transgenic rice with the ferritin gene. Plant Sci. 164: 371-378.

Venegas-Calerón, M., Sayanova, O., and Napier, J. A. 2010. An alternative to fish oils: Metabolic engineering of oil-seed crops to produce omega-3 long chain polyunsaturated fatty acids. Prog. Lipid Res. 49: 108-119.

Wei, C., Qin, F., Zhu, L., Zhou, W., Chen, Y., Wang, Y., Gu, M., and Liu, Q. 2010. Microstructure and ultrastructure of high-amylose rice resistant starch granules modified by antisense RNA inhibition of starch branching enzyme. J. Agric. Food Chem. 58: 1224-1232.

Wei, Q., Wang, Q. Y., Feng, Z. H., Wang, B., Zhang, Y. F., and Yang, Q. 2012. Increased accumulation of anthocyanins in transgenic potato tubers by overexpressing the 3GT gene. Plant Biotechnol. Rep. 6: 69-75.

Welch, R. M., Norvell, W. A., Schaefer, S. C., Shaff, J. E., and Kochian, L. V. 1993. Induction of iron (III) and copper (II) reduction in pea (Pisum sativum L.) roots by $\mathrm{Fe}$ and $\mathrm{Cu}$ status: does the root cell plasmalemma $\mathrm{Fe}$ (III)-chelate reductase perform a general role in regulating cation uptake? Planta 190: $555-561$. 
Welch, R. M. 2002. The impact of mineral nutrients in food crops on global human health. Plant and Soil 247: 83-90.

White, P. J., and Broadley, M. R. 2009. Biofortification of crops with seven mineral elements often lacking in human diets-iron, zinc, copper, calcium, magnesium, selenium and iodine. New Phytol. 182: 49-84.

Wirth, J., Poletti, S., Aeschlimann, B., Yakandawala, N., Drosse, B., Osorio, S., Tohge, T., Fernie, A. R., Günther, D., Gruissem, W., and Sautter, C. 2009. Rice endosperm iron biofortification by targeted and synergistic action of nicotianamine synthase and ferritin. Plant Biotechnol. J. 7: 631-644.

World Health Organization (WHO). 2012. Programmes and projects, nutrition topics, vitamin A deficiency. (http://www.who.int/nutrition/topics/ $\mathrm{vad} / \mathrm{en} / \mathrm{index} . \mathrm{html}$. Accessed Jan. 2013).

Yang, C. Z., Shu, X. L., Zhang, L. L., Wang, X. Y., Zhao, H. J., Ma, C. X., and Wu, D. X. 2006. Starch properties of mutant rice high in resistant starch. $J$. Agric. Food Chem. 54: 523-528.

Yano, M., Okuno, K., Kawakami, J., Satoh, H., and Omura, T. 1985. High amylose mutants of rice, Oryza sativa L. Theor. Appl. Genet. 69: 253-257.

Ye, X. D., Al Babili, S., Kloti, A., Zhang, J., Lucca, P., Beyer, P., and Potrykus, I. 2000 . Engineering the provitamin $\mathrm{A}(\beta$-carotene) biosynthetic pathway into (carotenoid-free) rice endosperm. Science 287: 303-305.

Yu, B., Lydiate, D. J., Young, L. W., Schafer, U. A., and Hannoufa, A. 2008. Enhancing the carotenoid content of Brassica napus seeds by downregulating lycopene epsilon cyclase. Transgenic Res. 17: 573-585.

Zhang, Y., Jung, C. S., and De Jong, W. S. 2009. Genetic analysis of pigmented tuber flesh in potato. Theor. Appl. Genet. 119: 143-150.
Zhang, Y., Li, H., Shu, W., Zhang, C., Zhang, W., and Ye, Z. 2011a. Suppressed expression of ascorbate oxidase gene promotes ascorbic acid accumulation in tomato fruit. Plant Mol. Biol. Rep. 29: 638-645.

Zhang, Y., Li, H., Shu, W., Zhang, C., and Ye, Z. 2011b. RNA interference of a mitochondrial $A P X$ gene improves vitamin $\mathrm{C}$ accumulation in tomato fruit. Sci. Hortic. 129: 220-226.

Zhang, G. Y., Liu R. R., Xu, G., Zhang, P., Li, Y., Tang, K. X., Liang, G. H., and Liu, Q. Q. 2012. Increased $\alpha$-tocotrienol content in seeds of transgenic rice overexpressing Arabidopsis $\gamma$-tocopherol methyltransferase. Transgenic Res. 22: 89-99.

Zhao, G., Li, M., Zhang, D., Li, X., Wu, Z., Ci, X., Xie, C., Bai, L., Lu, Z., Chen, L., Hao, Z., and Zhang, S. 2012. Kernel lysine content does not increase in some maize opaque 2 mutants. Planta 235: 205-215.

Zhou, X., Van Eck, J., and Li, L. 2008. Use of the cauliflower Or gene for improving crop nutritional quality. Biotechnol. Annu. Rev. 14: 171-190.

Zhu, C., Sanahuja, G., Yuan, D., Farre, G., Arjo, G., Berman, J., ZorrillaLopez, U., Banakar, R., Bai, C., Perez Massot, E., Bassie, L., Capell, T., and Christou, P. 2012. Biofortification of plants with altered antioxidant content and composition: genetic engineering strategies. Plant Biotechnol. J. doi: 10.1111/j.1467-7652.2012.00740.x

Zimmermann, M. B., and Hurrell, R. F. 2002. Improving iron, zinc and vitamin A nutrition through plant biotechnology. Curr. Opin. Biotech. 13: 142-145.

Zuidmeer, L., Goldhahn, K., Rona, R. J., Gislason, D., Madsen, C., Summers, C., Sodergren, E., Dahlstrom, J., Lindner, T., Sigurdardottir, S. T., McBride, D., and Keil, T. 2008. The prevalence of plant food allergies: a systematic review. J. Allergy Clinical Immun. 121: 1210-1218. 